\title{
Number and its Application Psychologically Considered
}

\section{E. Phillips}

To cite this article: D. E. Phillips (1897) Number and its Application Psychologically Considered, The Pedagogical Seminary, 5:2, 221-281, DOI: 10.1080/08919402.1897.10534358

To link to this article: http://dx.doi.org/10.1080/08919402.1897.10534358

曲 Published online: 28 Aug 2012.

Submit your article to this journal $\asymp$

Џ Article views: 3

Q View related articles $\longleftarrow$

Citing articles: 2 View citing articles 5 


\section{NUMBER AND ITS APPLICATION PSYCHOLOGI-}

CALLY CONSIDERED.

D. E. PhIL,IIPS, Clark University.

\section{The Background OF OUR Number CONCEPT.}

In the consideration of the subject now to be discussed, I propose to introduce and co-ordinate several phases and considerable work not yet found in any single treatment of the subject; to present a brief digest of the leading lines of thought on Number and Mathematics for primary and secondary schools from the pedagogical and psychological standpoint ; and, lastly, to present my original investigations. Whatever merit may attach itself to this article I believe the greatest will consist in bringing together considerable material generally ignored or overlooked in treating the psychology of number, and in the genetic treatment of the subject. It appears that the most natural treatment will be to consider (I) the background of our number concept, (2) its development, (3) the original investigations, (4) the special application of the number concept to arithmetic, (5) the conclusion.

I will first review some experimental work which at first thought may appear to have little to do with the question under consideration, but which really underlies the whole psychology of counting. In 1868 Vierordt experimented on time-impressions from the beating of a metronome, reproducing them after the lapse of a short period. The indifference point, the length of interval more easily and accurately judged than any other above or below, was not the same for each individual, but varied between $1.5 \mathrm{sec}$. and $3.5 \mathrm{sec}$. For himself this interval was from 2.2 to $2.5 \mathrm{sec}$, when through the sense of hearing, ${ }^{1}$ and twelve impressions could be distinguished if caught in a certain rhythm. Mach performed some experiments by the method of just perceptible differences as to the recognition of the equality of two time intervals. It was found to be most accurate at about $.37 \mathrm{sec}$. and in proportion as one varied from this standard it was necessary to increase the difference between the standard and the interval for comparison in order to recognize their equality. ${ }^{2}$ Kallert carried on several similar experiments in

1 Wundt's Phys. Psych., S. 78r.

2 Wundt's Phys. Psych., S. 785. 
Wundt's laboratory, where two metronomes were used; one giving off a constant series, and the other varied intervals for comparison with the standard. Experiments on seven persons for intervals from .4 to $.5 \mathrm{sec}$. showed the indifference point to be between .7 and $.8 \mathrm{sec}^{1}$ Estel and Mehner fixed the indifference point at .7 I sec., and treated of the multiplication of the indifference point. ${ }^{2}$ Dietze performed some experiments to determine the greatest number of metronome beats that could be repeated, and could be recognized to be the same in the repeated as in the original series. The largest series tended to group themselves into rhythmic multiples which he thought could not be suppressed. The largest number was forty and obtained by five groups of eight each. ${ }^{8}$ Most of the experiments mentioned above were performed in Wundt's laboratory and under his directions.

Mr. Stevens published in Mind the result of I 35 experiments on seven different individuals. "Of these, I I 4 point to this fundamental principle: That there is an interval of time (the value of which varies between .53 and $.87 \mathrm{sec}$.) which can be reproduced with considerable accuracy; but with all other intervals an error is made, which is plus for those above and minus for those below the indifference point, the average of which was about .7I sec." 4 The direction of the variation as stated here is directly opposite that found in all of the experiments above mentioned, but the methods were different.

Dr. Hall and Prof. Jastrow performed a series of experiments by setting up a number of cogs following no order. One cog was put in as an avertissement at the most favorable interval of about .75 sec., and the observer sought to count the clicks. Each series of observations was preceded by a preparatory series of clicks which was arranged so as to exclude any considerable variation, and thereby largely eliminate the element of fatigue. After sufficient revolutions of the drum to satisfy the observer, the record was taken and another number set up. From this work it is concluded that counting objects or impressions is a very complex process, that "impressions in a series must be distinguished from each other, that from 20 to 40 beats per sec. can be distinguished by the average ear without passing into one tone, that 4 or even three clicks must be farther apart than two, that counting requires a series of innervations, if not of actual muscular contractions, and the matching or pairing of the terms in two series in consciousness; that counting is more

\footnotetext{
1 Philosophische Studien, Bd. i, Heft. I, S. 88.

2 Philosophische Studien, Bd. ii, Heft. I, S. 37 ; and Bd. ii, Heft. 4, S. 546 .
}

\footnotetext{
3 'Wundt's Philos. Studien, II, 362.

4 Mind, Vol. XV, p. 394.
} 
than tallying by ones; it is giving names to each position in a series. These names are difficult to pronounce, and some become more prominent by means of the greater time or effort they require. This in part accounts for the tendency to count with a system of accents. When the observer is behind in counting and clicks appear to be lost, he has ceased to give attention to the auditory series, having caught the tempo in the beginning and perceives only the innervations which expand all short intervals." 1

Dr. Nichols has made a review of the work on these lines in his article on The Psychology of Time, and concludes that nearly all persons, under nearly all conditions, find a particular length of interval more easily and accurately judged than any other, that this interval is very variable for different individuals, that the sign of the Constant Error is usually constant in both directions from the Indifference Point, that, when the norm and reproduction are single, the Constant Error is minus for intervals longer, and plus for intervals shorter than the Indifference Point, when the norm and reproductions are multiples, we have exactly the reverse. ${ }^{2}$ Later, Dr. Nichols, after some very extensive experiments, asserts this same individual variation, finds the Indifference Point to be about .81 sec., and concludes that " time measurements are memories of certain most striking rhythmical, habit-inducing, and oft-occurring outer occurrences, such as particular watch or clock strokes, the varying lengths and shadows of morning, noon and night, etc." 8

Dr. Nichols has lately published a small work on Our Notions of Number and Space. It is founded on a great number of tests made on the tongue, forehead, abdomen, etc., with pins in a cardboard. From two to five pins were used, arranged in lines, triangles, squares, etc. On the whole four pins were guessed more frequently than 3 or 5 . "The more distinct and differentiated the separate terms of a presentation become, the more distinctly do they become numerical presentations. To formulate the genesis of numerical presentation we must determine the laws governing the simultaneous and successive combinations of separate points. The greater the number of points in any given distance the less accurate and clear these numerical presentations, and vice versa." 4 Small numbers were over-estimated, and large ones under-estimated. "Its origin and foundation must be fundamentally placed in the following law : Presentation of Numbers, of Distance, and of

1 Mind, Vol. XI, No. 4I, pp. 57-6r.

2 American Journal of Psychology, Vol. III, p. 529

s American Journal of Psychology, Vol. IV, p. Io7.

4 Our Notions of Number and Space, p. 184. 
all Spatial Figures, and arrangements in general are alike based, primarily, upon serial events, differing greatly in mode, such as become characteristic of those modes of presentation which we call numerical, external and spatial, but all of them governed by the same fundamental laws of relationship. By reason of this, all simultaneous presentations are dependent upon, and expressive of, the several modes of serial occurrence out of which, through life, they have evolved, and become differentiated." 1

Again, the work on Rhythm, by Dr. Bolton, will be seen to bear strongly on this subject. The preliminary part calls attention to the rhythm in the pulse, respiration, walking, speaking, attention, etc. In respiration the rhythm is about 15 to 20 minutes apart, the simplest voice utterances are primarily rhythmical. Nothing is more striking than the effect of thythm on children and savages, and no one can avoid the moving of muscles when the rhythm is strong and clear. The instrument gave opportunity for variation in intensity at any place, and intervals of time could be made between 2, 3, 4, 5, 6 or 8 clicks. The rhythmical grouping of sounds was the same in every case, and the same was found by Deitze in the work to which I have already referred; and Wundt thought it impossible to restrain this grouping absolutely. It is done by intensifying certain sounds and subordinating others. Many say it is the same peculiar periodicity as they observe in the ticking of a clock. Others, when asked to count them, said they counted 4 or 2 as the case might be and began again. The subjects were found to be unconsciously keeping time by tapping, nodding, etc., at every second or fourth click. When movement was restrained in one muscle it was likely to appear elsewhere. These movements are the condition of rhythmical grouping. The accented sounds occupy the first place in the series and the 4-group appears to be composed of two 2-groups. "The conception of a rhythm demands a perfectly regular sequence of impressions within the limits of about 1.0 sec. and 0.1 sec." "When attention is moderate the number of clicks falling into groups vary with the rate. Slower than a certain rate no rhythm is felt. With more rapid 2 clicks form a group. Faster still, 4 clicks form a group.", 2

Bechterew found that with two series of strokes, of which one was larger than the other, coming simultaneously at the most favorable rate of $0.3 \mathrm{sec}$, , he could distinguish a group of 18 from one of $18+1 .^{8}$

Several tests have been made regarding the eye-span. "If

\footnotetext{
${ }^{1}$ Our Notions of Number and Space, p. 200.

American Journal of Psychology, Vol. VI, pp. 145-237.

3 James' Psychology, Vol. I, p. 407.
} 
you throw a handful of marbles on the floor," says Hamilton, "you will find it difficult to view at once more than six, or seven at most, without confusion, but if you group them into twos, threes, or fives, you can comprehend as many groups as you can units; because the mind considers these groups as units." I Prof. James says : "If a lot of dots or strokes on a piece of paper be exhibited for a moment to a person in normal condition, with the request that he say how many are there, he will find that they break into groups in his mind's eye, and that whilst he is analyzing and counting one group in his memory the others dissolve. In short the impression made by the dots changes rapidly into something else. In the trancesubject, on the contrary, it seems to stick; I find that persons in the hypnotic state easily count the dots in the mind's eye so long as they do not much exceed twenty in number." 2

Jevon threw beans into a box and found that 3 and 4 were always guessed correctly, 5 correctly ro2 times out of 107, and 6 , 120 times out of $147 .^{8} \mathrm{Mr}$. Cattell exposed to the eye for . or sec. cards with short ruled lines, varying from 4 to 15 in number. With 4 or 5 no mistakes were made, but for higher numbers the tendency was to under-estimate rather than overestimate. He tried similar experiments with letters and figures, with practically the same results. ${ }^{4}$

Schumann made some experiments on memory in which letters were posted at regular intervals on a revolving drum, and observed through a slit. It was observed that when any rate was attended to for sometime, any change in the rate caused errors in judgment that would not have existed had the previous adjustment not occurred. The same was found to be true with metronome beats. He thinks the sensory centers are the seat of these phenomena, that they adjust themselves to a given rhythm, and rather expect excitations at a given time. Similar errors were found in measuring by drawing the fingers along a scale by motion of the arm. ${ }^{5}$ Bourdon tested roo children from 8 to 20 years old by pronouncing random figures, letters, and syllables, at the rate of roo per minute. Ninety-four could reproduce accurately 5 figures. Six, seven, and eight were reproduced by only a few. Figures were much more easily reproduced than letters or syllables, and the power improved a little with age. ${ }^{B}$

\footnotetext{
$\perp$ Lectures on Metaphysics, Lecture XIV.

Psychology, Vol I, p. 407 .

sature, Vol. III, p. $28 \mathrm{r}$.

4 Philosophische Studien, III, I2I ff.

s Pychology of Time, by Nichols, AmericanJournal of Psychology, Voi. III, p. 522.

'Philosophique, Aout, '94.
} 
Dr. Bolton performed some experiments on the MemorySpan in children, by reading miscellaneously numbers about two-fifths sec. apart. He concludes that the memory-span increases with age rather than with intelligence, that for pupils of public schools it is six, and that the power of visualization plays an important part. ${ }^{1}$

Mr. Johnson has given us the results of similar tests on Feeble-Minded Children in which it appears that some groups surpass the normal children of same age as given above by Bolton and Bourdon, but the average falls below that of normal children. The tables indicate some relation of memory-span to intelligence, yet it is so high that we cannot consider it commensurate with the degree of intelligence. They are ear-minded rather than eye-minded. ${ }^{2}$

In and back of the material that is herein presented we are to seek the proper approach to the whole subject of Numbers if we are ever to treat them in a psychological and pedagogical manner, and to throw light on the most poorly taught subject in our schools. In most treatments on this subject a mistake is made in treating it either from the standpoint of adult psychology, sometimes philosophy, or in considering a concept as having a sudden birth, rather than stages of development. That the concept makes its first appearance in consciousness with the word or language symbol that represents it is a pedagogical misconception once very prevalent, and yet assumed by many who have written on the subject of Number and Mathematics. In Dewey and McLellan's practical part of The Psychology of Number one would infer that they believe that the child enters school with a very low, if any, number concept.

Again there is too much tendency to treat certain concepts or ideas as having their origin wholly in a single sense; such as time to the ear, space to muscular movement, and number to the eye. Without doubt the evolution of individual concepts is the proper approach to intellectual evolution, and the concepts now so vivid to man doubtless have a long and interesting history in their development through the lower animals, and in the race, which somewhat corresponds to their continual development in the individual from the dawn to the close of life. Before we can clearly discern the fundamental character that distinguishes one concept from another we must at least consider its evolution in the individual. In most, if not all, of our concepts it will be found that different senses play an important part in their formation, that they are fed, not by a single stream, but by several, and pass through various metamorphic periods.

1 American Journal of Psychology, Vol. IV, p. 363.

2 Peddagogical Seminary, Vol. III. p. 246. 
Sight plays such a dominant part in the development of the number concept that most have sought its origin in the observation of things. Dewey and McLellan assert that numbers are not obtained from things, but put into things. "The idea," they continue, "that number is to be traced to measurement and measurement back to adjustments of activity, is the key to the entire treatment of number as presented in these pages."'1 That is to say, our number concept is developed from our necessity to measure things. Civilization imposed upon us this necessity. Had they called the chapter on the Origin of the Number Concept the Development of the Number Concept it would have more nearly included the facts. But it is absurd to think of a savage attempting to measure a given quantity without any concept of numbers.

Lefevre, whose work is in many respects scholarly and unique, says : "Primary number (the early number concept) is a normal and universal creation of the human mind; it is purely the product of a rational process - an abstraction from a group of objects which represents their individual existence. The concept one is only in contrast with the concept many. The fundamental concept is prior to, prerequisite for, not derived from, counting." 2 To say that it is a "normal and universal creation of the human mind " is only to drop into the old way of dodging psychological difficulties. In the above quotation we have the inference that recognition of numbers in groups is the necessary stage out of which counting is developed. Most teaching of numbers is now founded on such a supposition, the falsity of which I shall speak later. Concerning the ratio or measuring idea, the rational process, on which both of the above works are based, I will show hereafter that such has a place, but that it is a totally different thing from the number series.

"By number," says Schubert, "we understand the result of counting or enumeration, which involves the ordinary or number sign, and the word standing for the thing counted; as five men, seven cities, and to ascend from named to unnamed numbers the notion of addition is necessary." 8

This is sufficient to present the general drift of most discussions on the origin of the number concept, and before following this line further I wish to show the rudimentary stages that are prerequisite to this part of the subject, and then to co-ordinate this in its proper place. They would have done well had they not seized upon a part of the problem as the whole of it.

The first step is surely the formation of a series-idea. Changes in consciousness are continually taking place, produced

1 Psychology of Number, p. 52.

2 Number and its Algebra, p. 20.

8 The Monist, Notion and Definition of Number, April, 94. 
by the varying impressions from all the senses. Consciousness is not one continuous impression but an innumerable multitude of successive changes. Which one of the senses plays the first and most important part in the series-idea, we are perhaps unable to determine. We cannot go as far as Preyer, who claims that the number concept is derived from the sense of hearing; or Munsterberg, who appears to derive time chiefly from the rhythmic processes of breathing; or Mark, who says that time is the result of the consciousness of continuous metabolic changes; or, like Nichols, find the origin of space and number in touch. As already stated, without doubt different senses contribute to these ideas. The tactile sense very early produces an endless series of changes in consciousness which soon become vaguely recognized as distinct both in time and space; sound continually plays its part after the first few hours of life; random noises, voices, ticking and striking of the clock, all contribute to the formation of the seriesidea; the succession of night and day continues to greet the eye, objects come and go before the field of vision ; hunger and satisfaction periodically occupy a place in consciousness; functional processes, especially circulation and respiration, play an important part, the movements of a child, first by others, then its own - all these, in process of time, establish firmly the series-idea which exists long before the number-name series. The earliest and most rudimentary form of knowledge in the cognitive sense is a knowledge of a series of changes. This precedes all external knowledge of things.

Since most of the foregoing experiments relate to time, the question as to what this has to do with numbers has naturally arisen. Simply because they have primarily the same origin and are fundamentally the same. Many errors arise simply because such abstract notions are considered under the form in which they occur most frequently in adult life. Although time and number may seem now quite distinct, yet these abstract notions have more in common than is usually supposed. Certain number of clock spaces or of passing events give us a time measure. The hunter or laborer depending upon measuring the distance of the sun from the horizon, is entirely lost if clouds obscure the sun. The power to measure a certain time in hours or days depends upon the power to reproduce the events that have occurred during its lapse. The aged, being unable to remember the passing events, have little sense of time. Some series of succession is the norm by which we judge time. Time is also used to express number; a day's journey once stood for a definite number of miles. Some savages use the seasons and the days of the moon to designate certain numbers. "Representing equal units, and groups of equal units, of any order 
whatever, and being, as it were, created at any moment for the purpose of calculation, numerical symbols," says Spencer, " seem, at first sight, independent alike of space and time. The fact is, however, exactly the reverse." " "The conception of both number and motion," says Ladd, " involves both space and time."2 Figures or symbols are applied indiscriminately to any series of successions. Later we shall see that some of the strange mental phenomena in the application of numbers, and perhaps the relation of geometry to other mathematics, are traceable to the fact that this series-idea, established by a series of outer existing occurrences, embody the rudiments of the time, space, and number concepts.

This series-idea, established by a multitude of successive and rhythmical sensations conveyed through the different senses, ceases to be symbolized by different touch sensations, circulation, breathing, and movements, by sounds, clock strokes, etc., by varying objects in the field of vision, and becomes a general idea applicable to any series of successions. That this seriesidea is the first step, and that it becomes quite abstract, will appear evident when all of the facts are co-ordinated. Long before there is any conscious idea of number, children delight in reproducing or following a series of any kind. I have recorded 9I striking cases of this kind. Watch them throw down a given number of blocks time and time again, repeat a series of sounds; several record cases where children repeat the strokes of the clock, sometimes very accurately. A boy under two years of age rolled, one after another, ten mud balls down an incline, marking one each time until all contained a little cross. The successive nods or motions of the head that children so often go through before any attempt to count, are the same that nearly all children make in counting. Behind such activity the series-idea is manifest. But mathematical prodigies and savages furnish unmistakable proof of this early stage in the origin of our number concept. The former have the series-idea highly abstracted and developed before any names are given to the series. When Mondeux and others spent their early days in arranging and piling up pebbles, they were not forming a number concept, but simply endeavoring to symbolize the steps in the series-idea. Many of their combinations made without any knowledge of number names are astonishing. Mondeux said : "I did not know there was such a word as multiply, but I made my tables with peas and pebbles." 8 He could neither read nor write, and knew no symbols such as we use, when Jacoby found him. Inaudi, whom Binet has

\footnotetext{
1 Synthetic Philosophy, Vol. II, p. 38.

2 Psychology, Descriptive and Explanatory, p. 499.

${ }^{3}$ Scripture, American Journal of Psychology, Vol. IV.
} 
examined very extensively, first used any words, then learned the number names from I to 100 from his brother, and demanded more. He was then only six. ${ }^{1}$ Without number names he performed calculations that to most would appear wholly incredible. At the age of 3 years Gauss is said to have corrected his father who paid his servants at evening and for extra hours. Fuller, Ampère, Bidder, Mondeux, Buxton, Gauss, Whately, Colburn, and Safford learned numbers and their values before figures. Why are children so eager for number symbols? Many want the "last number," but are never satisfied with any number given. Dr. T- says his little girl has very much annoyed them by asking for the last number. Number names neither mark the origin nor limit the number concept.

Prof. Conant says that no tribes have been discovered to be without some number concept. But it is often limited to the numbers $I$ and 2 , or $I, 2$, and $3 .{ }^{2}$ Here we have a work that is a misnomer, since it deals only with the naming of the series. No one has any right to suppose a savage tribe cannot connt beyond the current words for numbers. In fact they can and do count further by the gesture language.

I now wish to show that this series-idea becomes abstract, and hence some symbols of representation are necessary. Numerical symbols must be considered as purely representative. So are the fingers, sticks, notches, pebbles, etc., of the savage and the mathematical prodigy. How many other forms of rudimentary representation there may be we cannot tell. One can easily conceive that the difference of the strain of consciousness in grasping two series, or different successions, might roughly stand as a symbol. The child that has never seen but one dog cannot, in any sense, have what we call the abstract idea "dog." It is only after many and different kinds have been observed that the idea ceases to represent some particular one or quality. When there is a rapid presentation of many objects belonging to a class the marks are most likely to go unnoticed and an abstract idea is uncousciously formed. Suppose no name is given to these presentations; nevertheless the idea would be gradually forming and most likely to be symbolized in its first stages of development. The abstract seriesidea has a similar evolution, only much more complex, less conscious, and more highly developed. It may be well to note here that in speaking of the abstract series-idea I do not mean it in the sense in which we speak of the abstract notion of virtue or of God. But such is more in the nascent and un-

Psychologie des Grand Calculateurs, p. 28.

2 The Number Concept-its Origin and Development. 
conscious period of development. It is the inheritance of latent experiences, of an infinite repetition of them, implanting the vague idea of an endless succession. It corresponds to the vague abstraction which children show in applying strange names to common objects. Succession of some kind is the earliest and most continuous thing in consciousness. Series of innervations, touches, sounds, sights, etc., are the most constant things in consciousness; one series only gives way to another. Of course we are now speaking in terms of a rudimentary consciousness, and in going back to such a stage one is most likely to carry with him bis present mental habits; and, since the eye symbols are so much more convenient now, and have such an irresistible influence over our concepts, it is hard to recognize that it has ever been otherwise and that there has been a gradual substitution. Thought is carried on in substituted symbols almost to the entire exclusion of the original ones, and without recognition that they derive their meaning from other sources at an earlier period. Certainly the prevailing opinion is that the number concept is derived through the sense of sight by the observation of things, or comparison of quantity. To what serious pedagogical and psychological mistakes this may lead is readily observable.

On what other ground than that which has been presented can we explain the facts as we find them in children? Children first name the series without reference to objects of any kind. Every attempt to instruct children in numbers shows that the series-idea is highly abstract. On making a test of 39 children in the kindergarten, I found that 33 of them counted without the slightest reference to the objects to be counted, always running the series far ahead of the objects. Nearly every primary teacher I have consulted says that for sometime children count in this manner, and the same is confirmed in the 616 returns to be considered later. Three hundred and fourteen out of $34 \mathrm{I}$ answering this question say the series gets ahead. Of the 39 mentioned above I found that all but two could count Ioo, yet their teacher said she had no idea they knew any number beyond Io. " $\mathrm{M}$ - knew number names long before numbers themselves, and applied them to anything indiscriminately, the number seldom agreeing with the number of objects; when she was only five she begged to be told "all the numbers there are.'" Mathematical prodigies, as already pointed out, have the seriesidea most firmly fixed, and to them it generally remains a meaningless abstraction. Again children have regard for only the rhythmical order of the number names. "Paul being asked how many puppies the next door neighbor had, replied that he had three. His father said he had four. The child said 'No,' and proceeded to count as follows: 'Tip is naught, 
Bob is one, Nero is two, and Dandie is three." "The use of naught for one is not uncommon. Have children of the kindergarten count, and you will find that they leave out difficult names and carry on the series the same, often repeating without being conscious of it. One boy asserted his ability to count IOO, but in seven trials he never got beyond 69, always going back to 30 . He still thought he counted roo, and appeared to have no idea that he repeated. "M- when learning to count things or impressions would count eight, nine for one object. The number series always get ahead." "This child learned the figures in order: $i$. e., $I, 2,3,4$. He could tell them in this way up to forty, but if they were changed around he would not know but what it meant the same; he associated number with place or order only." " Most children I have taught," says an experienced teacher, " will learn the names independent of things. For sometime they do not associate them as how many of anything, but merely the name of the series." A- writes: "I knew a little girl who was taught the figures in this way because they were easier to make: I, 4, 7, 9, Io ; afterwards, 2, 3, 5, 6, 8. For a long time the child would count $\mathrm{I}, 4,7,9$, ro, $2,3,5,6,8$."

I cite in this connection the following statements collected from experienced teachers : D-. When the objects were beyond his counting series, $\mathrm{R}$ - would look ahead, and finding this to be the case would group two or three objects as one to come out all right. F- They use them promiscuously. Freddie counted seven sticks; when his mother changed the order, he counted them thus : $3,4,1,2,5,6,7 . \mathrm{C}-$. In nearly all of my experience with little children I find that number names are used as names alone, and thus the third one in a series of objects will be a three to the child, no matter if it be taken from the series or not. $\mathrm{L}-$. I placed little sticks before Willie and told him to touch each stick as he counted, but he was just as liable to touch three when he meant six or any other number. W- Children learn number names as they learn other words, by hearing them repeated. They use them without knowing their respective values. They apply them promiscuously calling three objects ten as the case may be. Very frequently they have the idea that the number name belongs to the object in whatever order among others it is placed.

The early period at which children learn to count is very significant. They learn to name the series and follow it before they learn letters, to read, or to write. Out of over I, Ioo persons, $90 \%$ are sure that they learned to count first. The supervisor of one of the large normal kindergartens writes as follows: "The tiniest children in our lowest room could count perfectly as far as eight, giving the names in order, and pro- 
nouncing perfectly after the first three or four weeks in school. I was surprised, for I knew that most of these sounds were not associated with any idea of number. I was curious to find out the reason for this occurrence and soon came upon it. The girl teaching in the room counted for gymnastics. The great enjoyment which these little people took in those eight words suggested to me that perhaps it was not so wrong as we have been told to teach children counting. The smaller children often carry on this counting to themselves after being seated, counting over and over. From the movement of their lips I can see that the charm is still upon them." This same delight is manifested until children are 8 or to years old.

A passion for counting when children first learn to follow the series is very common; 131 cases are reported, many of which are very interesting. J-A A little girl of seven years seemed to have an absorbing passion for counting everything. One day when at the Township Fair she counted all the chickens. She was once sent on an errand with the injunction to hurry. On the way home she walked on the railroad track and counted the ties. When half way home she forgot the number, so retraced her steps a half mile, and counted them again. $\mathrm{M}-$ Lucy, 6 yrs., having been turning the leaves of a new copy of Webster's International Dictionary, turned to me saying "This dictionary has — pages." I noticed that she read the number of the last page correctly. "Well, Lucy, how many leaves has the dictionary?" Her answer was a little laugh and " $O$, don't know, a great many. There are over a thousand." My approval delighted her, and she told me of her self-imposed task of counting a million. "I have counted to seventy thousand." "You have?" "Yes, I am counting a million." "How long will it take you ?" "O, I don't believe I ever can, it will take such a long time. I have been counting a long time," she said. An older sister of whom I inquired, thought that she had been counting for nearly a year. In several schools which I have visited, teachers have departed from their usual way of teaching by blocks, etc., just to show what a delight children take in counting. Why is this series named so early? Why such delight in counting? Why should these words be sought and caught so readily? The abstract series is behind it. The child is only keeping up the various activities of following an indefinite series in the various ways before mentioned, by a more convenient series of symbols. But the old signs are not lost at first.

A movement of some muscle, as the toe or finger, or nodding of the head, can be observed in nearly all children when counting at first. In fact many adults consciously or unconsciously do so. $\mathrm{J}$ - When I was small I always used my fingers to count. 
In fact am inclined to do it still, so strong is the habit. When the teacher forbade it I used my toes, moving them inside my shoes sometimes; at other times I remember producing a little sound in my throat as a counter. Again, when alone, I was addicted to tapping my fingers in succession. When I wished to remember I always counted off on my fingers in some way that it would be clearly stamped upon my mind. G-. Have seen children who were forbidden to count on their fingers make pressures upon their legs and sides with fingers or elbows. A - Used to tally with my little finger, but not allowed to do this, I tallied by rubbing two of my back teeth. F-W. When counting I tap one foot against the other for every count. $\mathrm{L}-$. When $\mathrm{I}_{4}$ years old was greatly embarrassed upon finding all the boys in school laughing at me. Upon investigation, found that while doing an example I counted everything up on my fingers. This revealed a habit which I was entirely unconscious of. $\mathrm{D}-$. In adding numbers greater than three I would always nod my head first toward one side then the other. I stopped that, for a long time I would think of nodding, but not really do so. In Bolton's work on counting clicks the subjects nodded or moved some muscle. If suppressed in one muscle it was likely to appear in another.

The fact that, at least nearly all children, no matter how taught, first learn to count independently of objects, in which the series-idea gets ahead, that they recognize three or four objects at first as individuals, calling the fourth one four even when set aside by itself, that counting proceeds independently of the order of number names, and often consists in a repetition of a few names as a means of following the series, that children early desire and learn these names ; such, taken with the earlier steps presented, furnish unmistakable evidence that the seriesidea has become an abstract concept. This is an important fact, the full significance of which will become manifest later.

Before passing to the next step, which is the naming of the series, let us call attention to certain rhythmical processes that must not be ignored, and which all the experiments on counting clicks, etc., show. Whatever fault may be found with these experiments it is evident that there is a favorable rate above and below which error is much more frequent, that it varies somewhat in different individuals and for the different senses, that the multiples are of great importance, that certain grouping is hard to avoid, and that accenting of certain numbers in the series and varying of the rate tend to modify the groups. Again circulation, respiration, etc., are not only continuous series processes, but each has a rhythm of its own. Then the countless modifications of compound rhythms, both organic and locomo- 
tive, whose effect may be only dimly perceptible, are never absent and their continual presence may produce an unexpected effect. In listening to the tick of a clock, or any continuous sequence of the kind, we divide it into groups. Several report cases where children have inquired why some "ticks" were longer than others. Number is not the result of any one of these units of consciousness, or rhythmical processes, nor of all of them. They are only a part that contribute to the seriesidea ; but what they especially do is to stamp, as it were, certain numbers of the series, and give them a dominance over the others.

In all of the returns nothing is more common than the preference children and adults give to certain numbers. Again this preference is often unconsciously manifested. Out of 600 returns Dr. Lancaster observed a decided preference for 18 . Many will not give their age, or any other number correctly if it fall on certain ones of the series. There are certain numbers of the series we unconsciously avoid thinking in. Odd numbers are geuerally disliked. Miss D- has a passion for counting everything to find whether it is even or odd, and is displeased if it is found to be odd. I have before me over roo expressions similar to the following: "Odd numbers always cause a kind of shrinking, as though some obstacle had arisen, while with even numbers comes a satisfied feeling." "The odd numbers seem to me to have something uncanny about them, and to be of less consequence, fullness, and beauty than the even numbers." Mrs. G- cannot endure having an odd number of anything in the house. Why do merchants price goods $\$ .29, \$ .47, \$ .99$, etc. ? Evidently there is some psychology of number here which is turned to their advantage. We are accustomed, as we say, to think in "round numbers." They appear to be marked "close"; but why should $\$ .47$ appear "closer" than $\$ .45$ ? A merchant told me he had sold more of the same article when marked $47 \mathrm{cts}$. than when marked $45 \mathrm{cts}$. Cases of dislike for some numbers could be mentioned almost indefinitely where no reason can be observed. Dr. Brown, in relating the incident of the extraordinary precocious girl Marjorie Fleming, gives the following as one of her sayings: "I am now going to tell you the most horrible and wretched plague, the most devilish thing is 8 times 8 and 7 times 7 ; it is what nature cannot endure." Four is every where a favorite number. It is the most important factor in Hindoo arithmetic, all figures and fractions being built upon multiples and fractions of it. ${ }^{1}$ Perhaps ten and its multiple stand next, then there is a great variety of choices. I have found nothing to indicate the existence of a number system

${ }^{1}$ Hindoo Arithmetic, Science, Vol. XXV, p. 254. 
founded on $6,7,8$, or 9 . Although I 2 contains within itself the greatest advantages as a base, it has never been found among savages; notwithstanding civilization has attempted to substitute it for the decimal system, yet it is not likely to prevail. Such is the persistency given to the original system of counting on fingers.

The force of the rhythmical processes may be observed in children's counting, even when counting by 2's, 4's, 5's, etc., which they so much like to do; the rhythm is often very marked, as $5,10,15,20,25,30$, or $2,4,6,8$, 10, 12, etc. Exactly in what order and in what manner these special units of the senses, and rhythmical functions modify the seriesidea we do not know, but all observations and experiments tend to show that they do. As I have already pointed out, the compounding of various elements of consciousness in early life. eventually merges into what seems unlike any one of them, yet when such mental activity is analyzed it yields its original component parts.

Let us now consider more fully the naming of the series, several points of which have been mentioned. The naming of the series generally goes in advance of its application to things, and the tendency of modern pedagogy has been to reverse this. This is founded on the false conception that the number concept originates from the observation of things, and the development of number names among savages is sometimes pointed out as proof, but the widely different conditions make such proof of little value. Civilized people have the names to apply to the abstract series, but the savage must invent names or symbols to represent an abstraction that must otherwise remain unexpressed. The fact that the concept is always in advance of the power to name shows that naming is only symbolizing it by means of a corresponding number of things. A few tribes have no word for even one. The Chequitos of Bolivia have none, and use etama, meaning alone. Tacanas have only what they borrowed from the Spanish. In the Gudang district only two numerals are used. The original inhabitants of Victoria had no numerals above two, yet they counted, and even recorded the days of the moon. For many years in India "moon" was used for one ; "eye," "wing," or " arm," for two ; veda, "age," or "ocean," for four, because they considered four oceans ; "season," for six, because they recognized six seasons; but here we see the idea of a recurring series of time must have preceded. A tribe in Australia and some of the Malay race, give names to their children in order of their birth, thus forming a number system extending to nine. The terminations are slightly changed for the girls. I have been told of a district 
in the U. S. where parents simply number their children according to birth. The moment any series of words is arranged in order in our mind, it becomes a counting machine. ${ }^{1}$

Whewell held that 2 and 2 make 4 is a necessary truth beyond what experience can give. It appears, however, that no such an assumption is necessary, when the concept is fully analyzed. That some number names are among the earliest forms in all languages only strengthens what $I$ have said concerning the very early and in many ways unconscious origin of the seriesidea. The use of the names of surrounding objects for numbers among savages gives no evidence that these ideas were derived from such objects. Such is but the endeavor of the mind to symbolize ideas gradually evolved as before indicated. The many words which children coin for their own use are not mere babblings, but represent ideas which seek some mode of representation. The adult will frequently fail to see any relation between the name and the object to which it is applied. When a child calls water "guga" and persists in the use of this word for two or three years, it evidently puts into such a word something not conveyed by the general name of the object. For example, a child calls water-melon " bum-bum." Evidently the leading idea conveyed by this word is the thumping common in testing the ripeness of the melon.

In all primitive counting the gesture or sign language comes first. $A h, a h, a h, a b, a h$, etc., are natural number words now represented by human machines-striking of clocks, etc. In Livy we read that a nail was driven into the wall of Minerva each year to record its age. The finger method seems to have been the most universal and lasting of all primitive means of counting. Hence the almost universal use of the decimal system, notwithstanding the superior advantages of the duodecimal system, also the prominence given to ten and its multiples. Nearly two-thirds of all number-forms make their first turn at ten, and those that do not almost always do so after reaching the multiples of teu. Sometimes the counting is continued on the toes to twenty and then a man stands for twenty. Most races count to ro, but the exceptions are varied and many. Counting by sticks, pebbles, notches, etc., is second. The Egyptians used simple strokes up to ro, and for the Io's special symbols were used. A simple stroke, pebble, or notch elsewhere can represent 10, 20, or 100. Traces of the same system are found in the system of tallying at games, etc. In several instances the numbers from $I$ to 9 have been represented by the first letters of the alphabet, the Io's by the next nine letters. Again multiplication found an express-

'Tylor's Primitive Culture, Vol. I, p. 258. 
ion by dots over the letters somewhat as we represent variations in vowel sounds. $a=1, \dot{a}=10, \ddot{a}=100: 0=8, \dot{o}=80$, etc. This system was used by the Greeks to 10,000. The Chinese never write 245 , but 2-100 4-105. A system of bars separating each order of the number was once common in Europe. ${ }^{1}$ Concerning the significance given to symbols and the relation of the number concept to intelligence I will have occasion to discuss later.

This is essentially the counting period, and any words that can be arranged into a series furnish all that is necessary. Counting is fundamental, and counting that is spontaneous, free from sensible observation, and from the strain of reason. A study of these original methods shows that multiplication was developed out of counting, and not from addition as nearly all text books treat it. Multiplication is counting. When children count by 4 's, etc., they accent the same as counting in gymnastics or music. When a child now counts on its fingers it simply reproduces a stage in the growth of the civilization of all nations.

I would emphasize again that during the counting period there is a somewhat spontaneous development of the number series-idea which Preyer has discussed in his Arithmogenesis ; that an immense momentum is given by a systematic series of names; and that these names are generally first learned and applied to objects later. A lady teacher told me that the Superintendent did not wish the teachers to allow the children to count on their fingers, but she failed to see why counting with horse-chestnuts was any better. Her children could hardly avoid using their fingers in counting other objects yet they followed the series to roo without hesitation or reference to their fingers. This spontaneous counting period, or naming and following the series, should precede its application to objects.

Mathematical prodigies exemplify this period in the highest degree, and in fact it is to this period of mathematical development that they belong. A true theory or presentation of numbers should co-ordinate all such material, but none of our systematic treatments have considered Number-forms, Individualization, or Dramatization, of numbers, Passion for counting, Mathematical prodigies, etc.; in fact the theories exclude any consideration of these facts as well as all the experimental work set forth in the beginning.

Take from the mathematical prodigy the power to manipulate the series in the four operations of Addition, Subtraction, Multiplication, and Division, and you have nothing worthy of attention. They seldom ever make a practical application of

\footnotetext{
${ }^{1}$ Number Systems by Conant, Penagogical Seminary, Vol. II, p. 5 I.
} 
their power to things or to business, but, carried away with the delight of counting, they remain in an exaggerated development of this mathematical period. In general they, at least, appear stupid, inactive, having little knowledge of, or interest in, any thing except their ability to make rapid combinations in the abstract series. Gauss presents the greatest exception to this statement, yet his power greatly declined. In spite of opportunity for improvement Colburn, Dase, and Mondeux's talents disappeared. Precocity in calculation commonly appears between the age of 3 and ro years. Not only do mathematical prodigies belong to the counting period, but we find this period prolonged and highly developed in many who have never attracted attention. Many have a passion for counting which they feel compelled to satisfy. In Messrs. Lindley and Partridge's work on Mental Automatisms, $81.3 \%$ of 495 cases, have counting habits. Some count anything that appeals to the senses, such as telegraph poles, strokes of a bell, ticks of a clock, etc.; some count by "one, two," "one, two," and so on. ${ }^{1}$ Some feel troubled if they fail to count all of the desired objects. Riding on cars seems to be most favorable to counting. Perhaps this is due partly to a rhythmical tendency, to the strong presentation of rapid succession; and to states of revery in which the centers are allowed to respond freely to the various series of changes. Mere abstract following of the names of the series is indulged in with great delight by $\mathrm{I}_{3} \mathrm{I}$ of the 616 returns now before me, and 23 frequently count themselves to sleep. Again counting is often indulged in unconsciously. Just as I have pointed out in a previous article that there are all degrees of number-forms from the most highly complex and elaborate, even of three dimension, to the simple fact that, at least $90 \%$ of all children conceive numbers as taking some direction, and nearly all adults have a similar feeling, or conceive large numbers as being "far away"; so the counting period in which all children find pleasure, and indulge to some degree when symbols are furnished, seems to be quite indefinite ; but undoubtedly this period is the genesis of such mental phenomena as just described of which the mathematical prodigy is the highest embodiment.

In my article on the genesis of Number-forms I tried to show that such originate during the period in which the series-idea is being named or the period of spontaneous counting. While the abstract series-idea is being named it is represented by a series of muscular movements as seen in children's counting, but in most cases these muscular movements are suppressed, or partly so at least, before the series is well applied to things, and

1 Pedagogical Seminary, Vol. V, p. 4I. 
hence we may expect to find some mental movement corresponding to these muscular movements. The mind struggles to symbolize the series in some way, and on the intellectual side we have some idea of movement given to numbers. This movement may be a mere idea of a vague, indefinite extension in space, or it may become quite definite, complex, fixed, and vivid. It appears then that number-forms have their inception mainly before the series-idea is applied to things, are due to the abstract nature of the series-idea, to suppressed muscular movements and to the long period of development in which the ideas of time, space, and series or number, were so vaguely separated, and of which number-forms stand as a proof.

Much has been said of late about the relation of geometry and numbers. And the tendency is to introduce a kind of "eyegeometry " along with numbers. Even Sylvester said in his address to the British Association: "Whenever I go deep enough I touch a geometrical bottom." If such a relation is shown to exist and has any value it is to be found in the relation of the space concept and the series concept in their nascent state, and the value of such a relation is determined by the degree of dependence yet existing.

\section{The Application of the Series to Things and IMPRESSIONS.}

The two steps already considered are the long and gradual formation and development of the series-idea established by an infinite succession of changes produced in consciousness from the beginning of conscious life, and the development of symbols or names representing a series of successions otherwise variously expressed. We have seen that the spontaneity of this period is so great that as soon as any words are arranged in order they are used as a counting machine, and that certain mathematical phenomena that have not, and cannot be co-ordinated in any other treatment, belong here. It next remains to show how these symbols are applied to objects and impressions. Seeing how readily and easily every child learns to count or follow the series even to IOO, every teacher and observer must be convinced that its application is the most conscious and difficult step yet reached.

At first the individual thing stands for the number. Two hundred and ninety-two cases are given where children count objects; as four people, and although all except one may have disappeared, yet if this be the last named it is still called four. In counting chairs, etc., no collection is recognized for sometime. Dogs, chickens, etc., are often counted, each standing for a number and not as a part of a quantity, just as the case already cited where the boy recognized four dogs, Tip as 
" naught," etc. Many cases of this kind occur in the early counting of children and among savages. Without doubt some of the strange psychological phenomena sometimes called dramatization and individualization of numbers, in which the numbers, sometimes to 20 or more, are invariably associated with, and thought of, as some object or person, finds a satisfactory explanation at this point. Four is a fat duck, 7 a tall man, 8 a pale faced woman, etc. $P$ - Five is a pig tail, 4 a box, 7 a tall woman, 9 a lazy man, i 1 a pair of match horses. $S-$ I always thought of 7 as my crippled father (one legged), and 8 as my grandmother, and 9 as my tall grandfather. Now it is very natural that the child that called his neighbor's dogs naught, one, two, three, if this association be kept up, will later modify the objects associated with these numbers in accordance with the ease or difficulty in using these numbers. Three may become a mean troublesome dog; two a good puppy trying to make things even; naught an indifferent, easy-going fellow. While I have no direct evidence of this, yet it seems a very natural step in association and a plausible explanation. It further appears that the object is dropped later, or an association based only on some operation in the use of numbers arises. Two is simply a good little figure, 7 is a bad number, 3 is mean and cheats others, II is a happy, go-lucky individual, $I_{3}$ is mean like $3 ; 25$ is a square, round-faced fellow, etc. Then we have a few cases where numbers seem to carry on a continual combat for certain places : thus, 7 tries to get into 14 , but is crowded out by 2 ; it then makes an effort for 28 or 35 , but being crowded out, after much difficulty gets into 49 , and so on with the various numbers. F-. Four seems disagreeable and devilish, because it turns its back upon every number into which it is put. A child of 6 yrs. says 9 is cranky and you cannot divide it into 2's at all. B-. The figure 4 always seemed so staid and firm to me, until I was told by a teacher that one of his pupils said that she always made the figure 4 to waltz time, and ever since then it has stood apart claiming an air of its own.

While such exceptional cases may seem entirely beyond the explanation given for the simpler forms, yet it is better to seek their explanation in some association in early steps in the development of number than to treat such as entirely outside the ordinary laws of association.

In the application of the series to things is where the child first encounters much difficulty, and this is much increased because the teacher not apprehending the full importance of this step tries to hurry the child over this point entirely too rapidly. It is here that we meet with so many systems and devices for teaching numbers.

It seems necessary, then, that we should first consider the quan- 
titative ratial-idea of numbers, held by Dewey \& McLellan, Graham, Speer, and Lefevre, to which reference has already been made. This is entirely different from the series-idea which has so far been under consideration. It is a reasoning process to which the series-idea is applied. The eye-span and ear-span, a summary of which has been given, in so far as they are purely such, are but quantitative relations of groups. In the case of the eye-span where we find the purest, if not the only, examples, in its last analysis, it is the simple recognition of a form. Many cases are reported where animals seem to have a high sense of numbers, such as various fowls that recognize the number of eggs, animals that recognize the number of young, or pigs, sometimes exhibited in shows, capable of playing cards. When a boy, I remember, a turkey hen that always quit her nest if a single egg was removed, even when the nest contained 7 or 8 ; but after sometime I found she could be thoroughly deceived by removing 3 and putting in 4 hen eggs. It was only necessary to make the general bulk or form appear the same. Such will be found to be the case with most of such examples. The card-playing pig simply recognizes a form, as may be observed by any one who will analyze their own mental operation in playing a game of cards. In order to make clearer the difference between the series-idea and this quantitative ratial-idea, I wish to state some observations made on children. In one of the large kindergartens I observed the children giving the combinations of eight. The lesson was conducted with 8 two-inch cubes by separating them into various combinations. The results were given by the children as if it were an instantaneous recognition of so many numbers. I then asked if other objects could be obtained, and tests were made with various other larger and smaller forms, and objects taken from my pockets ; but in every test it was evident that counting was the only guide if any accuracy was reached. Such tests were applied in four different schools to 65 children learning the combinations of Io. The result was such as to make it evident that in most cases the combinations and relations so readily recognized were more a matter of form than of number, and that individual enumeration was resorted to whenever any doubt existed. Again the same thing was found even in a more marked degree when tests were made by presenting dots to the eye. One teacher presented to her children five dots in nine different arrangements and in every case they were obliged to learn the form before the number could be recognized as five without counting. The same thing is found wherever such tests are made. One teacher states that after teaching the numbers for sometime by dots arranged on cards, she accidentally put some of the numbers on the board in a different arrangement, and 
was astonished to find a hesitancy in recognizing them. She then for the first time realized that she had been teaching form rather than number. It is fully believed that a close analysis will show many of the above results on the eye-span and earspan to be only the recognition of form, or that the result is obtained by rapid counting and grouping, which, occurring so often and so rapidly, gives no conscious mental activity unless special attention is paid to the operation. There are many cases where a judgment is immediately given, apparently without any reflection, and such have been counted instinctive; but close attention to such mental states reveals even to the individual the steps by which such a judgment was formed.

Mr. Speer's Primary Arithmetic is founded on the assumption that the end of arithmetic teaching is to induce judgments of relative magnitudes. It is rather curious how much quantitative judgments are insisted upon. The Dewey and McLellan idea is very much emphasized, and to the entire exclusion of any other side. Here we have a logical process of reasoning insisted upon to which the series-idea is applied. "Reasoning in arithmetic establishes equality of relations, reasoning in any subject equality or likeness of relations "1 By what authority can we make the science of numbers co-extensive with all reasoning? Number in its genesis is independent of any, or all, quantity, and the science of numbers is essentially the relation of one number in the series-idea to another. That some form of the series-idea may be applied to all, or at least, most processes of reasoning, I admit, but that is quite a different thing.

Dewey and McLellan, with those already mentioned, holding the same ratial-idea, fail to see that there are two sides to the application of the series to things, the logical analysis to which the series is applied and a more general comprehension and application of the series-idea. We are told that, "It requires considerable power of intellectual abstraction even to count three," 2 that " the manifestation of the conscious tendency in a child to count coincides then with the awakening in his mind of the conscious power of abstraction and generalization. This also indicates discrimination and relation." 8 The truth of such statements can be maintained only by giving counting a false or philosophic meaning not sustained by any of the facts connected with counting. It is a capital error leading to the worst pedagogical blunder to suppose that abstraction and generalization go hand in hand with counting, or to suppose that

1 Primary Arithmetic, p. 35 .

2 Dewey and Mcl,ellan's Psychology of Number, p. 25.

${ }^{8}$ Dewey and McLellan's Psychology of Number, p. 27. 
number has any such meaning. Counting chairs, tallying by beats, etc., are no signs of abstraction and generalization, neither is the power to manipulate the series in the four fundamental relations any sign of such. I have found many children whose number sense was very highly developed, yet very inferior to other children in the power of abstraction and generalization. If this were true, the general intelligence of savage races should go hand in hand with the development of their number concept, but the exceptions are so many and so varied that no one can draw any such a conclusion. Take from the mathematical prodigy the power to count and manipulate the relations of the series, and as a rule you have little of any kind of intelligence remaining. They are noted for their general stupidity in other lines. Every one who has lived among the negroes knows how much their number concept is in advance of their general intelligence. They are generally unable to read or write, or to form any abstraction or generalization, but never unable to count and in many cases to perform astonishing calculations. Take Thomas Fuller, the African slave, who died at the age of 80 , never having learned to read nor write, and was of very low intelligence, yet his arithmetical calculations are among the wonders of mental phenomena. This philosophical theory is not wide enough to cover all the facts. The ratial-idea is but a part of the philosophy of number and takes in but one part of the application of the series-idea.

In what does the comparison of two quantities differ from the comparison of two leaves? "Quantity is limited quality, and there is no quantity save where there is certain qualitative whole or limitation." 1 To carry out their quantitative ratialidea, and make number the "rational process" desired is to identify number with all reason. The application of the seriesidea to the logical processes of reason no more makes them identical than the giving of motion to a ball makes the ball and the motion identical. Some maintain that mathematical reasoning is different from other reasoning; but there is still a wide difference between the reasoning involved in the fundamental operations with the number-series, and mathematics taken as a whole. This philosophy not only ignores any such difference, but any other that might exist. " Reasoning in arithmetic establishes equality of relations, reasoning in any subject equality or likeness of relations." It is true that "all relation is a result of comparison," and we can hardly conceive reasoning that does not involve comparison in some way, and even an application of the series-idea, either definitely expressed or more or less distinctly understood. When a child asserts two leaves to be

${ }^{1}$ Psychology of Number, p. 57. 
alike or unlike there may be involved a geometrical comparison and a comparison of the intensity of color; but there is no expression of such on the part of the child, and it is greatly extending the idea of number to call it arithmetic. Even granting there is no strict line of demarcation either between reasoning in general and mathematical reasoning, or between general mathematical reasoning and the simple operations with numbers; yet there are certain marked stages of development and application that no one will think of identifying.

This application of numbers is the latest and most difficult step, and no attempt should be made to push it on the child before the proper time. The most general use of the series does not involve this comprehension and application of numbers. If drill, for the logical reason be the aim, such an application of the series at the proper age is, without doubt, of utmost value; but having seen an advocate of the ratial-idea labor long and hard with no result but confusion on the part of the pupils, I am convinced that it is a step demanding considerable abstraction and generalization, and of a nature not found in the more general or common applications of the series, such as made in ordinary counting and calculation.

\section{Resulis of Some ORIginal Investigation. ${ }^{1}$}

This part of the subject will include ( $I$ ) the examination of 616 returns on the syllabus on Number and Mathematics, (2) the result of 2,043 papers on numbers and arithmetic, collected from the first to the ninth grade inclusive.

The following syllabus was issued :

\section{NUMBER AND MATHEMATICS.}

I. Psychological and Anthropological.

(a) State cases where animals, or children who could not count, have distinguished, more or less, objects, as eggs, young, toys, etc. How fine was this discrimination, how shown, and other details?

(b) Describe games of instantaneous guessing of the number of objects in a group, noises in a series, inches, feet or rods in a given distance, surfaces, angles, etc.

(c) Describe cases of tallying by beats or counters, before counting, or before number names are known.

1 See also Genesis of Number Forms, American Journal of Psycholo$g y$, Vol. VIII, pp. 506-527. 
(d) How do children learn number names, and how use them, what changes of order, errors in learning to count things; does the object series or the number series get ahead? Describe fully cases where counting became a passion, and everything must be counted, also cases of school children who use fingers, move toes, nod, etc., or use other counters.

(e) Errors and order in learning figures, making or applying them. Do the figure forms have any moral or personal character, as : 8 looks happy, 7 cross, 4 solid, etc. ? Report fully when such associations exist. How different do Arabic and Roman numeral forms seem?

(f) Cases of number forms, $e . g$., the first 12 numbers being habitually associated with a dial or clock face, the first ten on a line, straight or curved, systems of dots, colors, etc. Do odd seem to you different from even numbers? Draw any number forms. How do you arrange days of the week or month, the musical scale?

(g) Cases of " eye geometry," or automatic puzzling over patterns of carpet, wall paper, bricks on sidewalks, strong fondness for tracing the forms of decorative ornamentation, spontaneous drawing of such patterns or development of them in the use of kindergarten material.

(h) Cases of children exceptionally forward in or fond of mathematics and those exceptionally backward. Describe any physical or mental peculiarities of such children, their other tastes and aversions, and account for this peculiarity. Especial$1 \mathrm{y}$, if you have a prodigy, try to find out just how (by what process) each cardinal operation is done ; the same of dullards.

(i) Describe any rare case of pupils who associate number processes with personal acts or dispositions, as $e . g$., four is peaceable, and dwells tranquilly with eight, but with seven it feels and acts out enmity, etc.

(j) Ask children of each grade what part of the year's mathematics they like best and least, and why, letting those of upper grammar and high school grades write out their answers.

(k) What figures or numbers give you, as well as your pupils, most trouble in adding or multiplying?

\section{Peidagogical. A. Elementary.}

(a) Please state how you would teach beginners. Describe your special methods with any phase of the work. Special drills.

(b) What mistakes are most common in- $I$, notation ; 2 , numeration; 3 , adding (oral and mental) ; 4, subtracting; 5 , multiplying ; 6 , division ; are these more or less if special accuracy is attempted?

(c) If you have tried (1) the Grube method, state its chief 
merit and defect, (2) the same of Colburn, or much mental arithmetic.

(d) When would you begin fractions, and briefly outline your method of (1) beginning, and (2) of teaching common denominator, etc.

(e) Should more intensive methods, a larger or less proportion of time, more mechanical drill of both memory and slate, and less rules and explanations be advised?

(f) Or is this pure form work, abstract and obsolete, and far from the pupil's experience, the traditional application to values too commercializing, and should the number relations grow out of observation, facts in zoölogy, botany, physics, astronomy, etc. ?

(g) What illustrative or other apparatus would you use for each stage thus far? I, How long should, e. $g$., four be illustrated by four girls, tops, apples, etc., before the child understands that it can apply to anything? Would you use any form of abacus, or Russian counters, and if so what, how and how long? Value of associating, e.g., I, with unicorn; 2 , with an ox ; 3 , with a trefoil ; 4 , with a quadruped ; 5 , with a star ; 6 , an insect, etc. ; also value of jointed figure, $e . g ., 8$ joints in the figure 8 , etc. Value of toy money, divided spheres, jointed rods, etc., for fractions. Do the marketing, shopping or trading stories, as a setting or motive for the pure number relations, help or hinder ; and how, why, instances? Do you know any rhymes, songs, puzzles, or games or any other device that may help some? What charts, or diagrams, or blackboard pictures are helpful?

\section{B. Higher ArithMETIC.}

(a) Of I, proportion ; 2 , percentage; 3 , roots and powers ; which should come first and which last, and briefly, how would you begin and proceed with each?

(b) What should be the place of weights, measures, moneys ?

(c) Of the business application of the science of pure number relations, as interest and partial payments, exchange and bills, commission and brokerage, banking, taxes, bonds, annuities, or of their application to science, as in mensuration, surveying, longitude and time, geography, astronomy, physics, etc. Which is most important? Which logically first and last, and how would you teach each?

(d) What apparatus would you advise for upper grammar and high school mathematics, as slates, globes, drawing instruments with verniers, cube root blocks, theodolite, weights and measures, graphic methods and charts, etc., etc.

(e) Name the best text book or books, in your judgment, with the ground of your preference. 


\section{Geometry and Algebra, etc.}

(a) At what point in arithmetic should geometry be begun and how, and how co-ordinated with arithmetic and algebra?

(b) Name best text book and method for beginners. How far, and if at all how should geometry be based-measurement, drawing, or the data of astronomy or physics?

(c) At what point should algebra begin and how?

(d) Should it be taught abstractly and formally at first or concretely, and if the latter, on what basis? Name best method and text books for beginners.

(e) At what stage of progress, or at what grade or age, would you begin trigonometry? Name best method and text book. How would you connect it with previous mathematical work, and what practical work, observation or experience would you make use of?

(f) At what stage of progress, grade and age would you begin calculus and how? Name best method and text book for beginners. How would you connect this work with (a) previous work, and (b) informal observation and experience?

Something over 800 returns were received, but nearly 200 were found of little value in any way. Nearly all of the returns relate only to the first part of the syllabus, however, about Ioo have something to say on the second part, and I3 papers treat it extensively.

Of the 616 reporting on the first part, 235 are men, $3^{19}$ women, 62 do not designate sex. No further attention is given to sex, since there is no difference of any note in the returns. Seventy-two per cent. are teachers; forty per cent. have taught over five years.

Animals, or Children who could not Count, Distinguished, More or Less, Objects, etc. One hundred and thirty-five cases were reported for children ; 170 for animals, the nature of which may be seen from the following: $\mathrm{G}$ - A cat with 3 kittens will miss I even before they are a day old. $\mathrm{R}-$. Bob used to bring 5 cows; if I were missing, would, of his own accord, go back after it. F-. Our guinea always leaves her nest if a single egg is removed. Have tried her time and time again. $\mathrm{D}$ - I have a dog that can count 5 . He will bark once if you hold out I finger, twice for 2 , and so on to 5 ; he will bark for sticks in the same manner. M-. Bruce, our dog, used to bring the hogs out of the meadow. When in the lot, he would look them over, and, if any were missing, would go back. M- Thomas, 32, cannot count above ro, yet he can 
split rails by the hundred and know just how much he has made. $\mathrm{H}$ - I I knew a boy, 4, who could play casino before he could count io. He seemed to know the value of the cards by the arrangement of the spots. $\mathrm{C}-$ Willie, only 3 , had 7 blocks with which he played. I took away 2 ; he observed no difference until he attempted to put them in the usual form. $\mathrm{He}$ then cried, saying some one had taken his block ; returning I did not satisfy him.

These examples are sufficient to make clear the general replies to this question. It will be seen at once that the difficulty encountered here is to determine when it is form and when it is number that is recognized. That animals have some number sense both as a succession and as a relation between magnitudes cannot well be denied, but, as I have already pointed out, much that passes as such is only the recognition of an individual form ; and this is certainly true in nine-tenths of the cases given for both animals and children.

Games of Instantaneous Guessing of the Number of Objects in a Group, Noises in a Series, etc. Two hundred and twentysix cases are given, and 73 different games. Much under this heading bears a close relation to some of the returns on Mental Automatisms, ${ }^{1}$ and in some respects to Dr. Lindley's Puzzle Interest. However, he finds guess-games and riddle-making to begin about 3 , and culminate from 5 to $8 .^{2}$ Only 59 in my returns mention the age of guess-games, and it is generally placed between 6 and 10 .

Of Tallying by Beats before Number Names are learned, 9I cases are given. $\mathrm{H}$ - Fred will stand by the window and tally as the rain-drops fall. $\mathrm{C}-$. Eddie, only 2, often repeats the strokes of the clock. F-. When I was about 3 I tapped my finger as the rain-drops fell. Also sorted a collection of pictures, making a mark for each one put aside. $\mathrm{H}$ - . B., 4, keeps tally by closing one finger as the clock strikes, etc., also by shaking his head when the piano is played. D- . F., 3, was playing "farm;" every now and then he put a stick up the water pipe. E. asked him why he did this. He said: "They will tell me how many times I go to mill." $\mathrm{H}-$ Children follow the series in various ways, sometime before the names are given. F- A boy, 5, will arrange piles of sticks of different sizes, and then lay aside one larger stick for each of the different piles.

On Learning Number Names, 34I give a definite answer; 3 I4 say that children learn them by rote as abstract words ; 27 ,

1 Lindley and Partridge, Pedagogical, Seminary, Vol. V.

${ }^{2}$ A Study of Puzzles, American Journal of Psychology, Vol. VIII, p. 450 . 
from objects. This is one of the most important topics discussed in the returns. Several cases have already been given in the first part of this article, and only a few need be added here. $\mathrm{P}$ - Children learn number names by imitation or by hearing them used, sometime before they know how to apply them. D- C. could count Ioo long before she could recognize 6 or even 4 objects. M-. They learn number names by hearing them and use them promiscuously, calling objects by number names. It is astonishing how readily, and how many children learn number names even to 100 while they have a very limited knowledge of their application.

The Application of the Series formed another very interesting topic to which there were 329 answers ; 292 may be classed as cases where they apply them indiscriminately ; 37 to objects. Some of the 37 do not seem to understand what is desired. They speak of children applying them to objects, and then state that children designate objects according to their order in the series wherever they may be placed. Practically all substantiate the fact that children apply number names indiscriminately or promiscuously. In this connection are found some of the most important facts for pedagugical treatment or teaching of numbers. R- C., 2, always uses 2 for everything, if he sees 5 birds he will say " 2." H-. When L. was 3 he would press the piano keys and say: "I key, 4 keys, 8 keys," etc. I have often observed him counting to himself, saying, " $1,5,8$, Io, 20, 3, 9," etc. S- Sarah will often put blocks in a pile by 2 's and count only by ones. M- Sometimes I have my children count objects they can handle, and, if they have any idea of how many to expect, when the series number begins to get ahead, they will put over two or more at a time.

I am indebted to Miss Shinn for a very accurate, extensive, and valuable record on the observation of a child from the 8th month to the 6th year, a very brief digest of which is presented : First indication of number, observing things in pairs at 8 months; at 16 had an inclination to enumerate similar things, by successively touching them, counted her fingers, but not in correct order ; at I 7 taking nuts out of a box, etc., one by one, time and time again ; at ig delighted to transfer objects one by one; number above duality was not conceived ; "more" has been used, can count, but has no idea of quantity above two. Taking out cards she would say: "De wu" each time, apparently understanding it. At 20 months she understood "all" of any objects. The idea of succession of units was evidently manifested in various ways. At 22 months she tried to count 5 ; her uncle counted his fingers, she held up hers and counted correctly to 5. Two days later one finger was held before her, she said, "one;" two, she said "three." Being asked to look again, 
she said: "four," and went mechanically through the list while only 2 were presented. For some time about the 25th month she would call more than 2 "two-three," could count to Io, but did not know 3. At 26 could count without help, if not allowed to count for both taking up and laying down; yet in the 28 month sometimes 2 appeared to mean only more than one. Was proud of her first independent counting, often chanted the numbers ; two days !ater, all alone, trying to count beyond Io, she said I I, I2, I4, I8, 15, 40; do not know how she picked it up. At 35 she could add the combinations to 6 , but only subtract one ; counted to 19 , stumbling on 7 and 17 ; also counted by repeating names at random. At $4 \frac{1}{2}$ years she counted to 5o. Four months later Miss Shinn began lessons in number with objects, she cared little for this, and apparently learned little. Her mother, taking her, dropped objects and made it frankly a lesson with a demand on the imagination. The child responded better to this and soon came rapidly into an understanding of numbers. She reduces all to counting, says she does it in her head. Though concrete terms are used, she does not think in such. At 5 years 8 months, could count 1,000 . The above is digested from 55 pages. ${ }^{1}$

Change of Order of Number Names. One hundred and seventeen such cases were tabulated. A close analysis was made to ascertain if any order was generally hit upon, but such was not found except that $7,9,11$, and 13 are omitted much more frequently than any other numbers. Eighty-nine, out of the II 7 cases reported, omit or misplace one or more of these numbers. Thirteen count almost entirely by using the even numbers, but no general rule prevails. This disregard for order shows that the child cares only for the series of successions, and that any suitable words will afford it a counting machine.

Does the Number Series, or Object Series Get Ahead? This question was answered by 181 ; of whom 151 say the number series; 30 , the object series. The facts revealed under this head are of the utmost significance. Sufficient cases have been cited in previous parts of the article. In the individual tests made on 66 children, $I$ found that children in the model school and even in the first grade counted with considerable difficulty if they were required to keep the object and the number series equal. It becomes quite a slow process. Mr. S. told me that his children would not get the number series ahead if he moved the objects over very slowly. The fact that children can hardly go fast enough when following the series only, seems strange, but simply indicates that the number series and its application to things are quite different.

${ }^{1}$ See page 232. 
A Passion for Counting is strongly emphasized by I31. By 43 it was carried over into adult life ; in 88 it was most extreme between 7 and Io, disappearing soon thereafter; 57 first had a passion for following the abstract series, later for counting things. The culmination of this passion between 7 and 10 indicates that it is the period when the number series is applied to the object series. Such may be designated as the counting period which in some is prolonged and higbly developed. Dr. Badanes does not specify any age for this counting period, but we infer from his suggestions on teaching numbers that it falls within this period. ${ }^{1} \mathrm{~B}-$ H. when only 5 , could really count 1,000 by IOO's, and did count 300 by saying ror, 102, IO3, etc. F- M. could count 100 rapidly when 3 . Counted everything she saw when 7 and 8 , and often counted time by seconds when alone. T-. Mary, at 8 , would stop to count the shutters on houses, count her steps; everything had to be counted or she was not satisfied. One night went to bed very unhappy because she could not count all the stars.

Counting on Fingers, by Movement of Toes, Head, etc., is noted by 260 . The reader is referred to what has been given on movements in counting. ${ }^{2} \mathrm{~F}$ - - In a school of 50 children I found that every one counted on their fingers, most of them on the sly, but some unconsciously. G_- I find that when children are forbidden to use their fingers, they will resort to some other movement, tapping the foot, moving the toe, head, or arm, even to any muscular contraction. In some late experiments on counting, involving considerable complexity, $\mathrm{Mr}$. Bohannon found that subjects could not count without making some movement. The motor element plays a large part in nearly all thinking; but any one giving attention to any series of succession will find this tendency stronger than in most other mental activity. The rhythmic nature is perhaps more effective.

Errors in Making Figures. One hundred and seventy-two errors are reported; 43 make 3 backward; 52,9 and $6 ; 31$ confuse 3 and $5 ; 28,9$ and $6 ; 18$ are miscellaneous. These may furnish minor points of interest for the teacher.

Individualization or Dramatization of Numbers. Only 35 cases are given. C-I I always thought of $I$ as tall and thin, 3 as cranky, 9 graceful, 7 stubborn. D-. When a child, numbers were always some real person to me; 3 a well known carpenter, 4 a heavy woman, 7 a lawyer always prosecuting 9 , etc. How this came to be I do not know, and cannot remem-

1 Falsity of the Grube Method.

2 See page 234. 
ber when they did not appear so in childhood, even now I am not entirely free from it.

How Different do Arabic and Roman Numerals seem brought forth some rather peculiar answers. Only 4 say they like the Roman numerals ; I 73 dislike them because they are "stiff," " dignified," " reserved," "vain," " used for state occasions," etc. ; 69 detest them because they are of " no use," and cannot see why letters must be used to express numbers. E-I I always thought them grand and stately, and took extra care to make them. G- Roman numerals seem like something foreign, always thought of Roman soldiers and avoided them when I could. A-C Thought they were meddlesome because they are both letters and numbers. $\mathrm{D}-$. Dignified, always associated them with kings. $\mathrm{H}-$. Always had a great significance to me as $I$ had seen them in the Bible, dreaded to use them. Do not like them now except on the clock. HArabic common ; Roman numerals something extraordinary, so brave looking. It would be interesting to relate several more of these returns; the clearness and earnestness with which every one is stated bear conviction that here are some psychological associations, somewhat common, but perhaps unsuspected. They certainly give valuable. hints on the laws of association which, if not valuable in themselves, throw light on certain phenomena that seem not to come under any laws of association, such as we have already mentioned, etc.

"Eye-Geometry" is indulged in by 150. All of this has been so well worked up in Mental Automatisms to which reference has been made that I deem it unnecessary to present the matter here.

Accounts of 19 children unusually bright in mathematics, and somewhat dull in other branches, are given; and 6 who are quite stupid in mathematics. One boy, 9, can read and write, but cannot learn to count.

The Likes and Dislikes in Mathematics are difficult to classify. Seventeen different parts are mentioned as being liked; 21 disliked. Three hundred and fifty-four mention some like or dislike. Since the manner of teaching, etc., modify one's taste so much, I shall cite only the points that seem to be free from this and of most interest. Fifty-five like Interest, none dislike it; while 48 dislike Stocks and Bonds, 2 express a liking for such. Mensuration is liked by 25 , disliked by 13 ; only 1 reporting "eye-geometry" dislikes mensuration ; 17 of those who report such like it. The G. C. D. and L. C. M. is detested by 23 ; 19 like Mechanical work; 12 detest problems; 14 girls and 9 boys hate the whole of arithmetic. Geometry is liked by 36 , disliked by I ; Algebra is liked by 34, disliked by I; but these nearly all come from a single school. Such are the points of 
any special interest. The prevailing reason for likes and dislikes was "useful," or " no use."

Besides the above, 260 papers from the $4^{\text {th }}$ and $5^{\text {th }}$ grades, in which children state their likes and dislikes, have been examined. In the $4^{\text {th }}$ grade 38 , out of 124 , dislike Long Division; 5 , G. C. D. : 22, Concrete Problems; 47, Fractions. Sixty-nine like Addition and Multiplication; 62, the Mechanical; 20, Decimals. In the $5^{\text {th }}$ grade 35 , out of 136 , dislike G. C. D. ; 14, Percentage; I9, Fractions; I6, Denominate Numbers. Sixty-two like Interest ; 28 , Decimals ; 18 , the whole of Arithmetic.

What Numbers Give Most Trouble in Adding or Multiplying? There were 440 returns received; 157 give 7 and $9 ; 88,7$ and $8 ; 34,6$ and $7 ; 42,7$ only; 18,9 only; $26,3,6$ and 8 . The others were miscellaneous. Seven is found in 327 cases, 9 in 204. Five say 9 is easy, always I less than Io. ${ }^{1}$

From the above returns it appears that we may justly conclude that there is a period of number development that precedes conscions counting, quite distinct in children, if not in animals ; that tallying by beats, sticks, etc., mark the spontaneous development of the series-idea; that number names are surely learned abstractly, or by rote ; that counting first proceeds by following the series names without any regard for the order of the name ; that number names are first applied promiscuously to objects in which the number represents the order of the object in the series and not a collection of objects; that guessgames and a passion for counting have a considerable place in child-life from 6 to ro, which is, to a great extent, a period of spontaneous counting; that children in their first application of the series to things run the series ahead; that a muscular movement of some kind is almost unavoidable with children when counting, and not uncommon among adults; that personalization of numbers may originate in the early application of the number series to things in which the person or thing stands for 4 , etc ; that Roman numerals are generally disliked ; that a spontaneous habit of forming geometrical figures exists among many ; that likes and dislikes of subjects in arithmetic depend in the main, upon the probable degree of usefulness in life, but

\footnotetext{
I On examining the U.S. Census for 1880 , it is found that those who guessed at their age, etc., have a decided preference for the fives and tens, also for even numbers. Analysis of ages from 28 to 42 for Ala., Mich., and U. S. as a whole, shows the most striking results. Those giving their age at 30 and $3 I$, being about as 4 to $I$ for Ala., as 5 to 2 for U.S.; at 40 and $4 \mathrm{I}$, as 5 to $\mathrm{I}$ for Ala., as I3 to 6 for Mich., as 3 to I for U.S.; at 47 and 48 , as 4 to 5 for Ala., as 6 to 7 for Mich., as 4 to 5 for U.S., etc. ${ }^{1}$ In various curves and diagrams the effect of even numbers is very discernible.
}

2 Favorite Numbers. Scientific A metican Supplement, March, I889. 
the word " useful" is not explained by those answering, and this is subject to various modifications of teaching, age, position, etc.

Of the 100 returns bearing on second part of the syllabus, 22 say that mistakes are most common in subtraction; 9 in multiplication (being more of it); I4 say mistakes are more common in oral than in written work; 38 , written work.

Twenty know nothing of the Grube Method; 17 have used it to advantage ; 28 think that fractions should come earlier; more mechanical drill is urged by 18 , and less of it by 28 . A., a graduate of Yale, says: "I was taught the numbers as a drill in memory. It was an exercise in which every one wished to excel. We recited our tables until our work with small numbers became almost a reflex action; never had any trouble using them." C- " Drill element is good, but it destroys the higher comprehension of numbers so necessary for development."

Forty-eight think that in the country children's number sense is so developed on entering school that objects are necessary only incidentally; 29 think there is much danger of carrying the objective illustration too far. M. writes that association is best acquired when it is casual and can be dwelt upon until the child will think " 5 " without thinking "star." Proportion is placed before percentage by 24 , after by 56 ; roots are placed after proportion by 34 ; last, or with mensuration, by 62 . Doubtless much of this depends upon former teaching, books used, etc.

Teachers in different places and schools were requested to give review exercises covering their regular work in arithmetic and to collect the papers for examination. I have examined 2,043 such papers, with the following results :

\begin{tabular}{|c|c|c|c|c|c|c|}
\hline Grade. & $\begin{array}{c}\text { No. of } \\
\text { Papers. }\end{array}$ & $\begin{array}{l}\text { No. of op- } \\
\text { erations or } \\
\text { problems. }\end{array}$ & $\begin{array}{c}\text { Total } \\
\text { miatakes. }\end{array}$ & $\begin{array}{c}\text { Confugion } \\
\text { of } \\
\text { operations. }\end{array}$ & $\begin{array}{l}\text { Mistakes } \\
\text { in } \\
\text { operation. }\end{array}$ & $\begin{array}{c}\text { Mistakes. } \\
\text { in } \\
\text { principle. }\end{array}$ \\
\hline $\begin{array}{l}\text { I. } \\
\text { II. } \\
\text { III. } \\
\text { IV. }\end{array}$ & $\begin{array}{r}405 \\
224 \\
550 \\
95 \\
\end{array}$ & $\begin{array}{r}6264 \\
3815 \\
11976 \\
272 \\
\end{array}$ & $\begin{array}{r}354 \\
694 \\
538 \\
31 \\
\end{array}$ & $\begin{array}{r}89 \\
137 \\
145 \\
27 \\
\end{array}$ & 66 & II \\
\hline \multirow[t]{2}{*}{$\begin{array}{c}\text { V. } \\
\text { VI. } \\
\text { VII. } \\
\text { VIII. }\end{array}$} & $\begin{array}{r}1274 \\
139 \\
140 \\
130 \\
380 \\
\end{array}$ & $\begin{array}{r}22327 \\
1604 \\
847 \\
1357 \\
2251 \\
\end{array}$ & $\begin{array}{r}1618 \\
818 \\
297 \\
359 \\
890 \\
\end{array}$ & 398 & $\begin{array}{l}15 \\
47 \\
21\end{array}$ & $\begin{array}{r}11 \\
9 \\
13\end{array}$ \\
\hline & 2043 & $283^{86}$ & 3982 & 398 & I 49 & 44 \\
\hline
\end{tabular}

By confusion of processes is meant that the child's work would have been correct in some other operation as $4+4=16$, or 7 - 
$2=9$. A large part of the work was not of such a nature as to give this information. Of the 1,618 mistakes made in the first four grades, 409 were of such a nature that it was impossible to tell whether they occurred from a confusion of processes or otherwise. Excluding these, about $33 \frac{13}{3} \%$ of all mistakes in these grades are results of the confusion of processes. This confusion appears greatest in $3^{\text {rd }}$ grade, but this is due to the fact that the 409 mistakes belong chiefly to the Ist and and grades. More than 540 papers involved problems, and an effort was made to classify the mistakes on these according to operation and principle. Teachers are fairly well convinced that mistakes in the four operations greatly dominate, even in the $7^{\text {th }}$ and 8 th grades. It is very evident that subtraction is more difficult than addition. A teacher of 19 years' experience writes: "Subtraction is the most fruitful source of mistakes even to the 6 th grade."

Two hundred and eighty-three papers on multiplication, involving 1,095 problems or multiplications, the majority of which contained three figures in multiplier and four in mnltiplicand, collected from the $9^{\text {th }}$ grade, are of some interest. Total number of mistakes in these are 691 ; 186 were made in multiplying by $9 ; 195$, by $8 ; 199$, by $7 ; 57$, by $6 ; 9$, by $5 ; 15$, by $4 ; 3$, by 2. There are certainly some indications that Mr. Walker's charge has a general application. It will be observed in the table that the total mistakes, in all grades, exceed the number of papers by more than one-half. Considerable material in other lines remains to be worked up.

\section{The Application of Numbers to Arithmetic.}

Under this heading will be considered, (I) A brief digest of some books and articles on arithmetic, (2) Suggestions on textbook making, (3) The result of the examination of 166 textbooks on primary and elementary mathematics.

Brevity may prevent a clear statement of a writer's view ; in many cases only a few of the leading points can be mentioned. No classification will be attempted. Reference has already been made to Dewey and McLellan's Psychology of Number, in which the Hegelian idea of number as ratio and quantity as limited quality dominates. Number is developed from measurement and measurement arises from the adjustment of activity. The ability to count is made to coincide with the power of $a b$ straction and generalization, requiring ability to hold the mind from being absorbed in the delights of seeing, hearing, etc. Counting trees, etc., can only give the idea of imperfect number since they are not conceived as a vague whole and broken up into parts of equal units. Two false methods of teaching numbers are in use, the one teaching numbers as a set of sym- 
bols, the other, as a direct property of objects. Neither, they say, takes into account the fact that number arises in and through the activity of mind in dealing with objects. A severe attack is made upon the Grube Method because unity is taken as one thing. In the measuring method unity may be 12 , a month, etc. The practical part everywhere shows evidence of an effort to join it to the theoretical, but the difficulty is likewise evident. Much of the practical part is common, and is found in use. The factor idea has its genesis in multiplication, multiplication in addition, division in subtraction; but neither is identical with the other.

Lefevre's Number and its Algebra has as its bottom principle the Continuity of Number and Mathematics. Number is continuous. Algebra was slowly developed out of the investigation of numbers, and geometry cannot apparently proceed without arithmetic. There is a more primary and essential connection than Euclid made in his Fifth Book. All definitions should be tentative and capable of expansion. The principle of continuity makes negatives, zeros, infinities, fractions, and all numbers alike. "Primary number is a discreet magnitude, and the product of rational processes." That ten is not a convenient base, that a distinction should be made between pure and applied arithmetic, that all multiplication is not repeated addition (i. e., $\sqrt{2} \times \sqrt{3}=\sqrt{6}$ ), that long division should be taught first and abbreviated as the mind becomes able, such are but a few of the practical points considered.

Schubert's article on Monism in Arithmetic bears on the same line of oneness in mathematics, but is not so clear, deducing the laws of addition and multiplication from algebraic formulas. The substance of Schubert's article on Notion and Definition of Number has already been cited. Speer's and Graham's arithmetics have been previously mentioned.

The Committee of Fifteen gives mathematics the second place of all studies. So long as individual differences which are qualitative in so far as they distinguish one part from another are considered, objects cannot be counted. When counted, the distinctions are dropped out of sight as indifferent. Counting is the fundamental operation, all others are devices for speeding this one. Fractions are much more complex than simple numbers, involving three steps instead of one, and comparison or ratio. This is the cause of the child's embarrassment on entering fractions and operations that imply ratio. The pupil descends to the simple and returns to the complex numbers. Decimals are still more difficult, and roots a still further step in ratio. It is an advance to be able to separate or analyze the concrete, whole impression, and consider the quantity apart by itself. But if arrested mental growth takes place here, the re- 
sult is deplorable. Without doubt such an arrest may take place by the too exclusive training in recognizing numerical relations.

The Committee of Ten recommend that the ordinary course in arithmetic should begin about the sixth year and be completed about the thirteenth; that the course should be abridged by omitting subjects that perplex and exhaust without giving any real mental discipline (that is the practical affords the best means of discipline); that the method of teaching should be thoroughly objective, and, as far as possible, inductive; that the text-book should be subordinated to the living teacher; that quickness and accuracy should be considered of great importance; that child geometry should begin in the kindergarten, and systematic instruction in geometry about the age of ten. The Conference declares that most of the improvements suggested on arithmetic " can be summed up under the two heads of giving the teaching a more concrete form, and paying more attention to facility and correctness in work."

Mrs. Hornbrook's Labotatory Method proceeds upon the plan of individual research on different subjects, and she is present during the work to "suggest." Those using this method lay stress on the flexibility of their plan and the previously unperceived differences found among many pupils. A class of 42 in geometry takes a few weeks in concrete work, only a part of the recitation being devoted to class work. The class is divided and inspectors are appointed over each division. She claims that it is related to "self-education," that it enables the mentally acute to advance rapidly, gives the dull ones time, and that the sympathy between pupils and teacher is strengthened. Mrs. Hornbrook has also given us a work on Concrete Geometry in which she wishes every beginning in lines, angles, squares, cubes, etc., to be made purely concrete, and to be worked out by the pupils. It is intended for grammar schools.

A Class in Geometry by Geo. Iles is a small pamphlet presenting the concrete aspect, and would begin geometry by observation; a house-lot and two fields tell us much geometry. Go from facts to law. The work starts off well, but it is difficult to see geometry in all that is said.

Alex. Hogg writes an article, More Geometry and Less Arithmetic, in which he maintains that arithmetic should not precede, but begin with, geometry. Fractions cannot be taught without geometry, and algebra is but a form of arithmetic, somewhat a connecting link between arithmetic and geometry.

In Jackman's treatment of the Relation of Arithmetic to Elementary Science, we have a somewhat new view taken. Studies are distinguished as thought studies and form studies. The former exist only logically, but not in ideal educational 
methods, yet it is impossible to exactly define and distinguish them. The study of number is classed as a form study. Arithmetic stands entrenched in the dogmas of the past, it should give us a broader and better outlook into nature. Exactness is necessary but has been greatly neglected, not for want of mathematics, but for want of proper application. Ninety per cent. of all problems in our arithmetics are either abstract or deal with something foreign to the pupil. They should be of things common and comprehensible. Arithmetic must be applied to science, and the mathematiral operation made incidental, but by no means accidental. Arithmetic is not to be the end, but a means to a more accurate end in thought studies, or science. Baldwin's Industrial Arithmetic is entirely practical, leads the pupil to discover for himself, follows much in the line of the work above mentioned.

Henry T. Eddy, in his address to the American Association, thinks the past teaching of arithmetic has been a failure largely because of an old idea of discipline that does not discipline. He insists upon more independent research, such as found in schools of technology, etc. Interest is awakened by use. Mathematical talents are not so rare as supposed. Much more could and should be done in less time.

The article on Two Paths in Arithmetic, by W. D. Mackintosh, first gives a brief presentation of the early development of counting. Multiplication is certainly the domain of counting, but our authors of text-books have referred it to addition. At first with objects the physical operations, addition and subtraction, were the important things; with multiplication, the mental processes. While the world is busy using the original way, the arithmetics go into group counting, requiring too much mental power, or more concentration than the child possesses. The chief point is the relation of one's possessions to himself. Ego is +, non-ego is-. In this simple fact is the foundation of plus and minus signs.

The falsity of the Grube Method is presented in a thesis by Dr. Badanes. The Grube Method ignores the process of counting, does not avail itself of the advantages of our decimal system of notation; it ignores the serial nature of numbers, begins with deduction instead of induction ; it destroys spontaneity, and confuses the child with too many operations with one number; it is a mere mechanism. He maintains that every operation from I to Io reduces necessarily to counting, which is fundamental. Only by real problems demanding solution can we explain the processes in arithmetic.

Directly opposed to this we find Prof. Safford, in his Mathematical Teaching and its Modern Methods, declaring that the Grube Method is unquestionably the correct method of teaching 
arithmetic, that the difficulty it presents to teachers is what has caused it to be so little and badly used. "Matter must be digested by the teacher not only in scientlfic form, but in the form in which it is to be taught." All learning in arithmetic should be by the method of discovery.

The Grube Method as originally given in Leitfaden für das Rechnen in der Elementarschule, nach den Grundsätzen einer heuristischen Methode may be briefly stated as follows: The leading idea in Grube's Method is undoubtedly in general use, but not often referred to as such. Saldon is right in saying that the leading principle is objective illustration. The second principle presents the four processes with each number before the next higher is taken up. No new number must be taken up until all the possible combinations have been learned. The first year is devoted to numbers from I to IO; the second, from to to 100 ; regular work in fractions is introduced in the fourth year. The first step is from the concrete to the abstract, or the universal quantitative character of numbers; the second proceeds from abstraction to application. The child's greatest difficulty is in applied numbers. Multiplication and division are only forms of addition and subtraction. In a way one operation contains all the others. In measuring or comparing numbers pupils must acquire the utmost mechanical skill. The various combinations are familiar to most every teacher.

Doubtless every one is familiar with Mr. Walker's address on Arithmetic in Boston Schools. He claims that the amount of time is in excess of that which should be devoted to arithmetic, while equally important branches demand more attention. $\mathrm{He}$ points out that the study is largely pursued by methods supposed to conduce to general mental training, which, in a degree, sacrifices that faculty and accuracy in numerical computation so essential in all the affairs of life; and that the exercises are so difficult and complex as to not only destroy their disciplinary value, but become a positive injury.

Peterson, Supervisor of Boston Schools, differs from the above in his address to the Board in 1887 . He claimed that the time should not be reduced; that arithmetic is especially important for developing mental concentration; that it is not an exercise in logic any more than running and eating are exercises in the science of hygiene; that pupils there are not inaccurate in number work ; and that since it has been ordered that simple numerical facts must be discovered by the aid of objects, much improvement has followed.

Prof. Newcomb considers arithmetic poorly taught, and suggests that it should be more like the actual lessons of life, and that some lessons be built on the elements of geometry.

Ginn's Addition Manual applies the word method to addition 
and subtraction. He maintains that two-thirds of all errors made are in these processes; that too much number work is given in the first two years; that bad habits are most that is learned; that the child should learn to read the only 45 combinations possible as he would so many words; that 1,2 , etc., are but another expression for 2, 5, etc. ; that subtraction should be left until addition is mastered ; that the signs + and - are not to be used until later; and that such is superior to the sign method, or the still more complicated Grube Method.

Some valuable hints are given in a pamphlet on Rapid Addition, by Sprague. The writer says that it grew out of experience in the counting-room. We do not need to make the teaching of addition easier, but slower. Grouping is the key to rapid addition, and the child should be taught the different combinations as words, and should learn how to break up others; such as $7+4+7$, where the 4 should be mentally broken into $2+$ 2 ; in all series, such as $4+7+10,7+$ I $1+15$, etc., the child should be taught that the result is three times the central figure.

Some statistical work has been done which must be considered. D. E. Smith has an article on Sex in Mathematics, based on 10, 5 I 8 examination papers. Of the men, $63.6 \%$ passed, $59.2 \%$ of the women. The average of the men passed was $83.7 \%$; of the women, $83.6 \%$. In arithmetic the men stood noticeably higher in every respect ; more of them pass, on the whole, and are better in geometry; the difference in algebra is in favor of the women. The same writer gives us an article on Arithmetic in Rural Schools, based on 4,000 reports from 19 normal schools. Twenty-six per cent. pronounce number names to themselves, $33 \%$ visualize, $12 \%$ imagine them written, and $75 \%$ were first taught to count by number names. Taste undergoes a marked change in passing from arithmetic to algebra and geometry ; on the whole, it is towards a liking for mathematics. About $46 \%$ think analysis the greatest difficulty in teaching arithmetic.

Some tests on Children's Ability to Reason have been made by Hancock by sending test problems to the different grades. Mistakes on same problems were almost as common at 14 as at 12. The movement to introduce algebra and geometry earlier is commended; less number work in lower grades and more arithmetic from 9 to 13 is advised. He concludes that practical arithmetic generally means money transactions; that it is doubtful if children can reason beyond their experience and environment; that practical teaching should utilize this fact; and that ability to solve arithmetical problems varies with the rate of growth, in which girls show a decrease at 9 or 10, and 13 , boys at 8 and 14.

A Study of the Mathematical Consciousness, by Miss Calkins, 
contains some points of interest. It is founded on replies from 87 women and 30 men, Harvard students. She concludes that on the whole the subjects have concrete rather than verbal memories; that the proportion of verbal memories is five times as large among those who do not like mathematics as among mathematicians, and one and two-thirds as great among algebraists as among geometricians; that students who prefer geometry are more likely to be mathematically inclined than those who prefer algebra; that ease in memorizing is at least as common among those who like mathematics as among other students ; that classification and reasoning ability is much more strongly developed in the mathematically inclined; that Huxley is wrong in saying that mathematics is an abstract science which knows nothing of experiment, of observation, of induction, and rests on deduction: and that no important distinction is made between men and women.

Methods of Mind Training is a small work by Miss Aiken, based chiefly on some short drills in the use of numbers. A revolving blackboard is used on which are placed figures which pupils observe for a few seconds, then reproduce in order, add, extract root, etc. In a few weeks, with five minutes' drill each morning, pupils showed astonishing results. Thirty-two miscellaneous numbers, such as 1789 , varying from tens to thousands, arranged in four columns, were repeated after a single glance. Figures with dots, minus or plus signs, etc., were repeated; a group of 20 objects recognized instantaneously. The object of these exercises is to cultivate the power of concentrating attention, to quicken perceptive faculties, to cultivate accuracy in seeing and hearing, and to discriminate by immediately observing similarities and differences. It is claimed that the results have been very marked in awakening dull, slowmoving minds to activity, and causing them to take delight in their newly acquired power; that its effects are seen in reading music and learning poetry ; that attention underlies the whole of memory, and this is the sure way to attention. Of course it is claimed that attention to these exercises will strengthen the attention for all and any other, and it is here that the claims will encounter greatest opposition.

The practical dominates in French education. This is quite marked in their text-books and treatises on arithmetic as well as in most of their text-books. As early as I 747 Barreme published L'Arithmétique au Le Livre Facile pour Apprendre 1'Arithmétique de foi-même, et sans Maître. One cannot help but be astonished at the comparative excellence of this book. The four fundamental processes are given nearly four times as much attention as other works give, until almost a century later. Division is presented only in the form of cancellation, the ar- 
rangement is good, and the explanations and diagrams seem somewhat modern.

Lacroix's Traité Élémentaire D'Arithmétique, written in $18 \mathrm{I}$, is well worth considering. It is to some extent both a practical and theoretical treatment of number and its different applications in arithmetic. In the comparison of different objects which fall under our senses, says the writer, we are able to perceive in all, an attribute or quality by which they are capable of being increased or diminished. Such appears, in general, under two forms : as a collection of many particular things, or, of many equally separated parts. (Does not this single sentence contain both the series-idea and the ratial-idea of number?) Soon comes a single whole without distinction of parts, it is as one conceives the distance between two points. The subjects in arithmetic are discussed and it is urged that fractions should be made the key to composite or compound numbers.

Some of the most interesting points from Dr. Scripture's article on Mathematical Prodigies have already been mentioned. In many cases of these mathematical prodigies the result is the only thing that seems to come in their minds. Bidder said it came in the short time it took him to announce the result. The velocity of mental processes cannot be adequately expressed. Precocity in counting is from 3 to 10 . Their great peculiarity is the visual images of numbers which they always carry about in their minds. Amperre, Bidder, and Mondeux learned their arithmetic from pebbles.

Binet and Henri find that the mnemonic does not retain figures, but substitutes something else, while the calculators retain the figures as such ; that the mnemonic is more powerful but slower than the natural memory for figures. More powerful because his substitution allows him to retain a number almost indefinite; slower because he must reproduce all the mnemonic phrases for numbers.

Binet's Psychologie des Grands Calculateurs et Joureurs D'Echers is full of points of interest. Much of it is consumed in the comparison of Inaudi and Diamandi, an account of which I have given in Genesis of Number Forms. ${ }^{1}$ Great calculators are, in general, from unknown or low parentage; they are either slow and dull in learning other things or void of interest in anything else, because they are absorbed in the pleasures and power of great calculations. Their power develops somewhat spontaneously and quite early, without aid and without knowledge of other things. Many of Mondeux's self-developed systems are deduced from algebraic formulas. Many chess-players were

${ }^{1}$ American Journal of Psychology, Vol. VIII, p. 521. 
questioned; all of them visualize, but only one sees the entire board when playing blind-folded. As a rule, they see only the part where the combat lies.

The Number Concept: Its Origin and Development, already referred to, gives us a full treatment of the development of number names and of counting among primitive peoples. Primitive methods, previously mentioned, are thoroughly presented. Even where the concept appears lowest some circumlocution expresses the difference between one and many. Much uniformity prevails in counting on fingers, nearly always beginning with little finger on left hand. It appears that races lowest in civilization have also the feeblest number sense, but there are many important exceptions. Some savage tribes carry their system to $10, \infty 00$ or even a million, while in many it is almost entirely absent. Leigh Hunt could not learn the multiplication table, and peasants in Russia have no idea of even a few hundred. The ability to count is always beyond the numerical vocabulary. Counting words are among the very first to appear in any language, yet they change less than any other part of a language. Kinship in tongue, otherwise remote, has been detected by these words. With the savage the number concept is entirely concrete. When number in the abstract is reached then reckoning ceases and arithmetic begins. The tables showing from whence savages obtain their numerals are valuable.

Several other valuable articles and books have been reviewed but space forbids a consideration of them here; however, a list of all so far consulted will be found in the bibliography at the close of this paper.

Suggestions on Text-Book Making. What is said under this head has grown out of eleven years' experience and the present investigation, and is in no wise intended to be dogmatical. The diversity of human intellects, human needs, human environments, child's spontaneity, psychic activity, and especially mental phenomena in dealing with number, demand that neither the teaching nor the text in arithmetic should be dominated by a single idea. For general use a textbook should be properly balanced between what is known as the practical and disciplinary use of arithmetic. It is true that each party claims to accomplish the best results in both ; but every one knows that most business men work by rules, tables of interest, etc. ; know and care little for the whys. It is possible to find good mathematicians well disciplined, but slow, inaccurate, and void of what is termed "good business sense."

In the presentation of numbers we must allow for the spontaneity of the child, for the knowledge of numbers already possessed on entering school, and for the manner in which it 
was acquired; begin on the knowledge of the series it already possesses, and make the transition from this to objects. Counting is fundamental and even combinations furnish the first step, hence counting by 2's, 3's, 4's, etc., furnish the first steps in multiplication. The difficulties of subtraction are greater and more lasting than those of addition, hence its introduction on beginning addition must at first be incidental. Care must be taken not to confuse the child by introducing too many processes at once. Children do not look at things with adult minds, and it is not necessary to know all about 4 in order to know any thing; the processes need not be isolated as they once were, and the simplest fractions may be incidentally introduced quite early, but they involve more relations and hence demand more mental power than the unit. A routine presentation of numbers by the same objects develop form rather than number. Problems such as, "How many twenty-sevenths in threeninths?" were solved by children 5 and 6 in the kindergarten. Ninths and twenty-sevenths were certainly names of some of the little cubes in their toy-box. ${ }^{1}$ Such mechanism may prove more detrimental than beneficial.

We must distinguish between a child's ability to perform operations in the relation of numbers and its power to understand language. Children often fail because they cannot read. A class of 14 failed on a problem concerning a ball with a cavity. Inquiry revealed the fact that only two knew the meaning of cavity. I have no statistics of value on which to base it, but my impression from this special study is that children's ability to reason in arithmetic comes later than Hancock concludes; that much of the early work is performed in obedience to a mechanical formula even without the knowledge of the teacher. In the returns, 49 consider the mathematical "insight" a rather sudden innovation; I suppose something like the learning of telegraphy as given by Horter and Bryan. ${ }^{2}$ This appears to be true in my own case, but it was certainly due to the manner of teaching and the excessive help received. Until further evidence this is a better explanation than to consider it a law of mind growth.

Arithmetical teaching must not be too formal. This is the rock on which our great advocates of analysis stumble. It must not be only an analysis, but a special analysis. Only a few days ago an ex-president of the University of West Virginia declared this to be the great evil of modern methods. "My child," said he, "can never understand my solution or see any meaning in it unless cast in a special form. Children's minds are set to a form." The child needs suggestions. Long and

${ }^{1}$ Grube's Method. F. Louis Soldan.

2 Studies in Telegraphic Language. Psychological Review, Jan., '97. 
formal analysis produces confusion and mechanism. Have you any devices in the use of numbers not given in your book or by your teacher? is a question I put to $\mathrm{I}, \mathrm{I} 24$ children, receiving 407 replies, including 182 devices or departures from the rules;

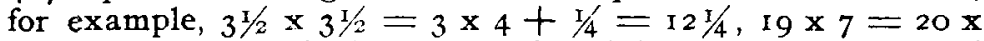
$7-7=133$. Skipping the 5 's in adding, keeping a record of them on fingers; never adding 5 to 27 , but 3 , then 2 ; dividing a number like 17 into two parts to multiply it, as $17 \times 6=$ Io $\times 6+7 \times 6$; never having anything to do with 9 , using so and subtracting ; counting percentage backwards ; subtracting a number in parts - these are some of the devices mentioned. An interesting example is given in Miss Shinn's observation already mentioned: "How many 2 's in 15 ?" she was asked when $4 \frac{1}{2}$. She replied: "There are three 5 's in 15 , and two 2 's in each 5 and $I$ over ; that makes six 2's, and 3 over makes one 2 and I over ; seven 2's and I over." A young man who had given up his university education came to me for private lessons in arithmetic. He knew absolutely nothing of the subject in book form, yet he was a good business trader. I have often dictated problems to him, the correct result of which he would announce before he had cumpleted taking it down; he was seldom ever able to tell me how he got the result, often receiving no encouragement of its correctness, and after prolonged effort would report unable to solve it. If not crushed by formalism the mind is almost unlimited in its variation.

Why nearly all advanced arithmetics should devote 60 or 100 pages to the four processes, when such has been preceded by one or two books treating them both oral and written, I fail to see. It is certainly not expected that such voluminous books will be placed in the hands of children. I remember when children used to begin in Ray's Third because it presented all of the primary steps, and both teacher and parent decided it was unnecessary to purchase the first books. This is frequently the practice now in the country. The evil results are readily discernible.

Decimals should grow out of common fractions, and in reading and writing decimals the child should know exactly the number of figures necessary for each decimal at least to millionths. This can be learned by proper drill in three recitations; then there will be no stumbling over either reading or writing them. This may be called mechanical, but anything is better than the usual confusion we see in enumerating. Make it rational also, that is all right; but immediate recognition of decimals is necessary. To avoid confusion in division, pointing off should precede the operation. Wentworth is the only one I know of giving both of these points.

Reference has already been made to the fact that the ratial- 
idea must not be the basis of number in all its development and application, and that as such it cannot explain all of the facts ; neither must its value and application be overlocked at the proper time and place. While some base everything upon it, others too much ignore it, even giving proportion a small corner in the last of their text-books. The series-idea undergoes various processes of development in its applications. In its pure mathematical sense, when applied to space and time, the number concept is greatly modified, and differs from its application to familiar tangible objects. In other words exact measure is different from applied numbers. Number in its first stages of application does not consider equality proper, but it is only when the idea of continuity is put into number, which is necessary to complete the oneness of mathematics, that this equality or ratial-nature is developed. Pure mathematical quantity and number are not identical. ${ }^{1}$

Number is not so simple nor so limited in its application. The rational process is preceded by a development which it does not take into consideration. Comparison is a process of reasoning to which the number series is applied, rather than from which it is developed. This pain is greater than that ; I enjoy eating more than playing; I am fatigued more than I was last night, are comparisons of subjective states to which the number concept may be applied in a very indefinite manner. But let none of this analysis stand as an argument against the use of the ratial-idea at the proper stage of development, or even its incidental introduction from the beginning; but it does not

${ }^{1}$ Since writing the above I have reviewed Russell's articie On the Relation of Number and Quantity, in Mind, Vol. VI, pp. 326-34I. It is the most masterly treatment of the ratial-conception of number I have seen, and states this difference clearer and stronger than I had conceived it. "Throughout this abstract development of number," says he, "the unit has become gradually more important and explicit. When it is quite explicit we get a third kind of number, which, outside our arithmetic books, is alone of importance. This kind I shall call applied number." Again, "the connection of quantity with number-we must conclude-is due partly to motives of convenience, but mainly to a confusion between two fundamentally distinct ways of regarding space and time. It must be maintained, therefore, that quantity applies to contents only when they are regarded as immediate data, and applies then only when such data are not understood. In this it differs from number, for number can, by abstraction, be applied to material perfectly understood. While things which can be numbered together must have some conception in common, things which can be measured against each other must have no conception not in common, and yet must differ." The idea of continuum must stand or fall with the relative justification of quantity as against number. Much stress is placed upon the distinction made between intensive and extensive quantity. All quantities must be reduced to spatial equivalents before they can be quantitatively treated. 
appear that children are capable of reasoning accurately or to much extent until 12.

Having supposed for several years that percentage was quite a blind process to most pupils, in which they closely follow formulas, and that the difficulty lay in the fact that they do not comprehend per cent. as a common fraction, either expressed or understood, I determined to make a test of 224 students, either teachers or preparing to teach. For this purpose 40 problems were prepared involving transactions in gain and loss expressed in common fractions ; $81.6 \%$ solved all of them ; the remainder missed, on an average, over five problems. Later the same problems, the words being changed and the fractions expressed in terms of per cent., were given to 212 of the same students; only $62 \%$ solved all, while the average number missed by the others was about 3 . It appears that a much more intelligible comprehension can be secured by an interpretation of per cent. in terms of common fractions, such as is well presented in Graham's arithmetic. There ought not to be so much isolation of so many subjects that come under percentage as though they were entirely new subjects. I can hardly account for so many likes for interest and so many dislikes for percentage, especially stocks and bonds.

The rapidly growing use of the Metric System and its exceeding simplicity demand for it more attention than is generally given. It must be remembered that Congress has authorized the use of the Metric System in many departments of the Civil Service.

All of the concrete problems should be followed by sufficient abstract problems to give a more general idea of the application of number. If proficiency and accuracy are to be obtained, the purely drill element cannor all be eliminated from arithmetic. As far as possible problems must grow out of the child's evvironment.

Upon the suggestions herein outlined a brief review will be made of texts in arithmetic now in circulation and those lately issued, so far as I have been able to ascertain.

The examination of $\mathrm{I} 66$ text-books on elementary and secondary mathematics reveals some important points, if they can only be put in a condensed, yet comprehensible form. Nearly all of these are arithmetics, because in arithmetic the application of number is of most interest.

Earlier Text-Books. Robert Record's Arithmetic (ed. I 590 and 1618 ) reads like a Bible; 260 pages are devoted to the four processes ; alligation follows fractions; dots are used for teaching the combinations of numbers; it contains 630 pages, of which fully 500 are consumed in discussion and explanation.

Edward Wingate's Practical Arithmetick and Artificial Arith- 
metick ( 1629 ) are two books, the latter is written to help the former by borrowed numbers from logarithms. Extensive tables are prepared in interest, etc. All the lower denominations in compound numbers are made out in decimals of the standard. He published another in 1676 , in which he first gives the name and number character of all numbers up to $1, \infty 00$ for English, Greek, and Roman notation.

Cocker's Arithmetic ( 1677 ) partakes largely of that idea of "sacredness" once attached to mathematics. "By the secret Influence of Divine Providence," say the author, "I have been instrumental to the Benefit of many : And now do with the same wonted Alacrity cast this, my Arithmetical mite into the public Treasury, beseaching the Almighty to grant the like Blessing to these as to my former Labors." The book has many commendable features, and, judging from the fact that there were 48 editions, must have been quite popular. It is largely taken up in discussion.

James Hadder's work ( 7 I9) is much like Record's. Tracing everything to the four fundamental operations, he makes such the dominant idea; but nearly all is devoted to explanation and discussion. Such is one of the chief characteristics of all the earlier books, perhaps somewhat made necessary by the limited knowledge of the teachers. Probably in this respect the contrast between the old and the new is more striking than in any other.

Gordon and Dobson's Arithmetic ( 177 I) contains many very curious problems, rather puzzles. Weights, measures, etc., are introduced just after division. Such is one of the most common qualities of all the old texts. Fractional money frequently follows simple addition, and this is still quite common in English texts. Taken all in all more prominence is given to fractional money, weights, measures, etc., than any other single subject; these nearly always follow the four operations and precede fractions. Temple gives addition of compound numbers on $5^{\text {th }}$ page.

Pike's Arithmetic (I793 and I797) makes one think of their early school days. Many of the rules, almost word for word, can be found in books somewhat modern. The $6 \%$ method is used and interest is placed last, save alligation. I cannot understand the prominence given to alligation by so many. In many it is near the middle, following fractions, but in some it precedes. Several borks develop all rules on the style of the catechism by fixed questions and answers; but never give a summarized statement of the rule. R. C. Smith and several others proceed with each step, as follows: $Q$. How do you begin to divide? A. As in short division. $Q$. How many steps are there? A. Four. Q. Name them. Such as this is found on every page. 
Walsh (1814) gives no rules, only a few suggestions to the teacher. Motto: Iter est breve per example. James Robinson (1825) introduces long division before short division. In this and other particulars it should be classed with texts of the last decade.

Emerson has the number series and their names to Ioo learned first. Butterworth has the pupil to express first in words, then in figures, even as high as $6,100,192,204$. Porter's Ready Reckoner ( 1843 ) applies cancellation to every part and gives every rule by directing what to place on each side of a vertical line. Hilliard's two volumes are full of devices and short cuts in arithmetic.

Colburn's Arithmetics (1849) once had such a wide circulation and the plan so well understood that little mention need be made here. This plan objects to explanation on the part of the teacher and leaves the child to work out his own salvation. Written work is discarded. The later editions have introduced much not found in the original. Horace Grant's Arithmetics ( 1861 ) presented in England the Inductive Method. Mental arithmetic is claimed to be of fundamental importance. Nearly all the work in both books is mental. The subjects treated are very much reduced; are on the same plan as Colburn's; were once quite popular in England. Walton's Pictorial Arithmetic (1866) is full of pictures of all kinds that may be counted; reduces it to object lessons. Burchett's Practical Geometry (1855) holds the lecture method by which the teacher makes drawings on the board, pupils take notes, and make careful drawings afterwards. No figures are given.

Leysenne's La Deuxième Année d'Arithmétique devotes considerable to compound numbers; square root follows numeration and decimals. It introduces geometry to a considerable extent, and the commercial element occupies a prominent place. It is in many respects an excellent book.

The general characteristics of the earlier text-books on arithmetic may be stated as follows : Extensive discussion and ex. planation which made the volumes comparatively large; the arrangement by which great prominence is given to fractional money, weights, etc. ; stress laid on proportion being placed before fractions in some cases; the assignment of interest rather to the last part of the book; and the peculiar problems, often puzzles. On the other hand, many of the presentations of primary number, such as Emerson's Elementary Lessons, have not been greatly improved upon; many sets of problems are unsurpassed. The short cuts and devices which business men use so much are obtained almost entirely from these old books. The disciplinary idea may be detected in many, yet, on the whole, the earlier books were dominated by the practical idea 
no less than those of the present day; but the practical was not so generally accepted.

Later Text-Books. Milne's Standard Arithmetic introduces many purely number problems in the simplest processes of addition and subtraction, etc. The presentation of decimals is defective; proportion is somewhat slighted; 7 pages of inadequate treatment of the metric system is presented near the close; percentage is likewise defective by not being based on common fractions ; mensuration is well treated, and the review problems are excellent. The book aims to be both disciplinary and practical.

White's New Arithmetic presents many commendable points. Counting by 4's, 7's, etc., is in strict harmony with the development of the number concept ; fractions, decimals, and the metric system are well presented. Percentage seems to be too much wedded to formulas. Proportion precedes roots in its proper place. Problems are practical and well graded.

1 Moore's Grammar School Arithmetic applies the Inductive or Laboratory method throughout. Not a single rule is given, and the pupil is left to devise the definite processes. First the concrete, then the abstract corresponding to it. The simple processes occupy $4^{8}$ pages, the presentation of which is very good; the treatment of fractions is up to date. The subjects are repeated somewhat on the Spiral-plan. Ton much space is devoted to denominate numbers. We can well see how such a book would be all right in the hands of competent teachers, but there is a gap between the subject matter therein presented and the child's knowledge that must be supplied some way. If all teachers were able to properly assist the child in developing the proper manner of procedure, this great objection would disappear, but the majority of teachers are young and inexperienced. I am unable, for example, to see anything to guide the inexperienced teacher and pupil to an understanding of decimals. Whether the book presupposes some knowledge of such, I do not know.

${ }^{2}$ Hewett's Arithmetics, Primary and Practical, are on a somewhat new plan, and in every way justifies the title Practical. The rules are few, suggestions to the point; little distinction of classes or cases problems is made; the pupil is left to sort his problems in percentage, etc., and to make the application as he must do in practical life ; all subjects not considered practical are omitted. A better treatment of percentage and interest I have not found. On some points the student is liable to confusion, which is a stumbling-block with all learners; decimals

${ }^{1}$ Lately published.

2 Lately published. 
are developed from the unit ; the metric system receives but a passing notice of 3 pages as the last subject. In the main the work is too true to a single idea.

1 E. E. West's Twentieth Century Arithmetic, in two parts, presents a few modifications of interest. The second part is the first grammar school text I have found that does not treat extensively the four processes. This opens with as extensive and complate consideration of fractions as can be found anywhere. Decimals and percentage might be improved; the metric system is well presented, and the equation of one unknown quantity is introduced in such an incidental manner that it cannot help but be beneficial to the student, and at the same time free from any opposition to those who oppose the logical method. The book is small but comprehensive, and devoted to the practical.

Walsh's work includes a series of three books, on what is called the Spiral-plan, that is taking a little of a subject and returning to it again, perhaps several times. This differs from the frequent review problems in that more subjects are introduced early in the course, and treated less extensively. The practical omission of rules and definitions is noticeable; decimals are well presented; the chapter on geometry adds to the work, for geometry should be introduced incidentally much earlier than it is. The equation is used especiallly in percentage and interest. Several systems of texts present something of this nature, but I have found nothing that carries this plan so far. If carried out in this form one cannot help but think that it will lead to a lack of organized knowledge, if not confusion on the part of the pupil.

'The Venable series subordinates the theoretical and technical to the practical. The Elementary is somewhat on the Grube style; it is good in the presentation of measures. The Practical devotes 63 pages to the four processes; rules are long; the metric system is placed in the appendix.

Sanford's work's are old in the presentation of elementary numbers; fractions and compound numbers are well treated; the arrangement is unsatisfactory.

Baldwin's Industrial Primary Arithmetic claims to be the natural way of teaching numbers, leads the pupil to discover for himself. Class work and seat work are separated. Everything is presented in the common, practical, business way. Arithmetic must be studied solely for its application to business life. It is the best example of the practical idea, pure and simple, I have seen.

Prince's Arithmetic by Grades includes eight small works on the Inductive plan, the wost excellent points of which are the

I Iately problished. 
treatment of fractions, the introduction of the elements of geometry in the $4^{\text {th }}$ grade which is gradually increased each year, and the excellently graded problems. There are no rules, but suggestions and diagrams somewhat take their place. If used in graded schools and by experienced teachers no difficulty would be encountered. They also repeat the topics in the grades. In the presentation of primary uumber some improvement might be made.

Graham's Common School Arithmetic has ratio as its fundamental principle, and is founded on the intensive or disciplinary idea. The same may be said of Speer's, McLellan and Ames's. Two elementary works by Miss Bacon go with Graham's. His work treats the four operations somewhat differently from most ; thus, $2 \times 4=8 ; 1 / 2 \times 8=4 ; 4 \times 3=12 ; 1 / 4 \times 12=3$. Tables of such are quite extended, and, without doubt, to much advantage, both in multiplication and in fractions. Proportion is treated more than usually and is placed before percentage; the metric system is practically ignored; decimals could be improved. Fractions and percentage are admirably treated. The work is wedded to the idea of ratio and discipline.

Speer's New Arithmetic, in two parts, is absolutely devoted to the idea of comparison as a means of developing accurate judgments. A set of blocks of various kinds and sizes go with each book. The Primary begins by having the child find or handle these solids; bring a larger or smaller one, the largest and smallest. Comparison in colors is introduced at once. Look at four colors, think the colors (eyes closed) from top down, from bottom up. Which is second from top, third from bottom, second from bottom, etc. ? Relative magnitudes of all kinds are pointed out, largest solid, smallest solid, tallest boy; compare the height of pupils, largest surfaces of solids, etc.; then an exercise comparing sounds, etc. Show the longest edge of the largest solid, shorter edges. Cut a slip, cut a longer one, shorter one, larger square. Draw a line, one a little longer, shorter, etc. Draw a line, separate into equal parts, show one-half of it. By means of such comparisons of blocks, lines, colors, etc., the work proceeds step by step. The Elementary is also accompanied by a large collection of blocks illustrating integral and fractional relations. Ratios consume the greater part; interest and percentage are developed from ratio. Much of this kind of work has been done in our best school, but only in a few instances has it been made the whole of arithmetical training. No other series of text-books follows such a line exclusively. McLellan and Ames's work claims to be founded on the idea of number as measurement, yet both the subject matter and the treatment are entirely different from Speer's. So far as I am able to judge, Miss Walter, of Willi- 
mantic Normal Training School, has been practicing Speer's plan for some years in the model school, in about as pure a form as it can be put. Doubtless such work should have a much larger place in our schools. The high value of comparison added to acute attention is of the utmost importance in all reasoning processes whatsoever. The great function of the work above cited, and to some degree of all the other books in this line, is to dress up thought and to make general thinking more acute No teacher should be blind to its great value, but at the same time such an exclusive treatment ignores some of the fundamental facts in the nature and application of number. One may be well trained in all the geometrical and quantitative comparisons and yet be void of good business sense in arithmetic.

1 McLellan and Ames's Public School Arithmetic is based on number as measurement. The ordinary drills in the four processes cover the first 74 pages ; many of these are pure abstract exercises in numbers, but money value and linear unit play an important part. The four processes are followed by four pages on Comparison of Numbers, and this by square root. How square root to three and even four places is to be made rational at this period of development one may well inquire. It must presuppose much more knowledge of arithmetic than the previous treatment indicates. Fractions are handled in an excellent manner ; decimals are made to grow out of the dollar and the metric system; however, the metric system is the last chapter in the book. The same difficulty to join the practical to the philosophic idea of number that is evident in The Psychology of Number is made still more evident by this book. One looks in vain to see in this work any great difference from half a score of others. It is by no means as true to the idea as Speer's.

Griffin's Supplementary Work in Arithmetic (1893) is a rather large work including lines, areas, volumes, bulk and percentage, and is based, in the main, on the measuring idea. Various figures and drawings are given and many questions concerning their comparison. If judiciously used by the teacher in connection with other work it cannot help but prove of great value. The author appears to have no special method or theory to present, nor does he think of making it the whole of arithmetical training.

Franklin's New Arithmetic, by Seaver and Walton, presents no new departure of note, but is none the less pedagogical. The First Book contains several commedable features. The processes are rather incidentally introduced, but not confused, and counting, in various ways, receives attention. The chief points of excellence in the Second Book are found in both the

'Lately published. 
number and character of the problems and the rather incidental introduction of subjects.

The Wentworth series has had such a wide circulation that they are doubtless familiar to all teachers. The Primary follows somewhat the Grube method of presentation, and the simplest fractions are introduced early by use of objects and diagrams. Decimals are presented and are followed by the most excellent primary treatment of percentage I have seen anywhere. His Practical Arithmetic contains 372 pages, and presents the usual elementary treatment of numbers in the four processes. That drill in the four processes is the main thing in arithmetic may be offered as a justification of this practice; but why children capable of handling this and having had the two previous ones, should need drill in adding $5+8$, etc., in subtracting $22-3$, etc., and in similar simple operations in multiplication and division, I do not understand. The treatment of decimals, common fractions, and percentage is not susceptible of much improvement, save that decimals precede common fractions, and little more prominence might be given to reading and writing decimals according to the number of figures required. This series is a medium between the purely disciplinary and the purely practical, between the purely rational and the purely mechanical in arithmetic, between the thoroughly inductive and the thoroughly deductive. They are neither dominated by a single idea nor spoiled by method.

Besides the above, Wheeler's Arithmetic, Primary Number Lessons and Advanced Arithmetic, by the State Board of Education, California, Ray's series, J. M. White's Oral, Brooks's Mental, Bailey's American, Robinson's series, and Atwood's Graded, arithmetics are used in different sections of the country, and several others are quite limited in their circulation. Other books which I have not been able to secure may be extensively used. On account of necessitated brevity and lack of space, I have thought it best to confine my review of later texts to those of this country, although several others have been examined.

The German books are quite conservative, introducing the practical, but clinging to the disciplinary. Each step must be thoroughly mastered, and mathematics taught as a unit. The French make much of the decimal or metric system of measures, etc. ; induction, as presented by Grant and Colburn, has not much place, books are seldom without some rules, but they are quite exact and clear. The English texts adhere to deduction in some form. In the oldest books currency, weights, etc., nearly always follow division, and occupy much space, and are often introduced with addition; alligation receives attention. The marks of the old are very evident in all of the new.

Among the great diversity of opinions in the articles and 
books above reviewed, it is evident that there are four general lines of thought: ( I) Those who hold and treat arithmetic as a system of logical reasoning, highly suited to develop the mind, and place it more on the plane of pure mathematics; (2) Those who consider arithmetic useful only, or in the main, for practical business life, and would make the shortest cut possible to this end; (3) Those who base all instruction on induction, omitting all rules and explanations, resorting to the laboratory method or method of self-discovery ; (4) Those who cling to the old idea of deduction from fixed principles or rules. Omitting some differences in the presentation of primary numbers, nearly all other differences, and many of these, are involved in these points. The first two classes differ concerning the end and the nature of arithmetic; the other two concerning the best means for obtaining the desired end. Those seeking discipline, or development of judgment, may use either the inductive or deductive method; likewise some maintain that the practical is best obtained by memorizing and applying rules ; others claim that the most direct and thorough way to secure the practical results is by induction from real transactions. Only a few occupy either of these extreme lines, and there are all grades of compromises, or attempts thereat. Perhaps few would claim to belong to the first or second classes as presented, especially the first, for those who make arithmetic a means to develop accurate judgments also claim to realize the best practical results.

That practice does not always conform to theory and philosophy is manifested in the texts on arithmetic. Notwithstanding the varying theories and methods discussed in prefaces, books, etc., one only needs to put aside about one-half dozen of our latest works, and the differences in the remainder are practically not worth mentioning. The teaching of arithmetic is the most traditional of all subjects; its methods have come down less changed than any other topic, and by many it is thought to be the worst. It is in the presentation of primary numbers that the devices of teaching are so opposite. The mathematical mind was a late development in the race, and so it is in the individual. Too much value is often attached to the abstract manipulation of numbers, and the believer in the concrete often fails to realize the necessity of an intellectual evolution into the higher forms of mathematics. "Skill in computing may be acquired without any intelligent apprehension of arithmetical science, and a profound insight into the truth and principles of arithmetic may be attained without much facility in using numbers." 


\section{Conclusion.}

The main inferences from this work may be briefly summarized as follows:

That the number concept is the outcome of a long process of development marked in the race and in the individual.

That the first step is the formation of a series-idea by the innumerable variety and successive changes in consciousness.

That this develops an abstract idea of succession, manifested in children's desire to follow in various ways any series, and especially in mathematical prodigies.

That prominence is given to certain members of the series by the various rhythmic processes as illustrated by the experimental work reviewed, and by the great preference given to certain numbers.

That there is a counting period quite marked in children and to which the mathematical prodigy belongs.

That the number, time, and space concepts are closely related, in their nascent state at least, and this relation gives number a wider application.

That dramatization of numbers, number forms, and prodigies belong to the counting period.

That some movement is perhaps unavoidable in the early stages of counting. If the motor element be a necessity of all thought, it is even more so in following an abstract series.

That the application of the series-idea to things is the second and more conscious step, hence the difficulty.

That number as measurement is not the whole of the development of number, but only the complimentary side of the seriesidea.

That number as measurement can by no means explain all the mental phenomena of numbers.

That the power to manipulate the series bears little or no relation to the development of reason and general judgments.

That number has applications not in a pure mathematical sense as an exact quantity.

That there is a great variety of mental phenomena found among children and adults in connection with numbers.

That the chief lines of discussion concerning number and texts on arithmetic are directed towards either the disciplinary or practical end, the deductive or inductive method of presentation.

That arithmetics and methods of teaching have remained, comparatively speaking, quite constant until the last few years.

That the chief defects in texts are found in the presentation of primary numbers, fractions, decimals, proportion and percentage.

That there is a general tendency in this and other countries 
to introduce many of the elements of geometry and, at least, the simpler uses of the equation into arithmetic, the former of which, at least, is to be commended.

That the authors of text-books seem to be searching for methods and often ignoring the manner in which the race and the child naturally acquire such knowledge.

That no method should ignore the long psychic and rudimentary stages of development. Yet if allowed to play too great a part, morbid conditions may be developed, such as seen in morbid counters, excessive counting on fingers, etc.

That the great diversity of human intellects, human needs, human environments, child's spontaneity, of mental phenomena in the development and application of number, forbid the exclusive use of any one orthodox method in teaching number and arithmetic. (We have already reached this generalization in teaching reading.)

That practical business training in arithmetic, and preparation for higher mathematics and abstract thinking in general are not identical, nor obtained in the same way.

I must express my great obligation to Drs. Hall, Burnham, and Sanford for valuable assistance - especially to Dr. Hall for suggestions and criticism; to Prof. Luckey, of University of Neb., to Prins. Barnes, of Fairmont Normal, W. Va., Deahl, of West Liberty, W. Va., Miss Williams, of Trenton, N. J., students of these institutions, and others, for valuable returns ; to Supt., teachers, and authorities of Worcester schools, for assistance and privileges ; to other schools rendering assistance ; to different book companies for granting the privilege to examine their publications and for books donated.

\section{BibliograpHy.}

Since this includes only the articles and books so far consulted, it must not, in anywise, he considered complete. It was necessary to omit the bibliography of text-books for the present.

ARNETh, A. Die Geschichte der reinen Mathematik. Stuttgart, 1852. Aldis, Mary S. The Great Giant Arithmos. London, $\mathbf{1 8 8 2}$.

Aiken, Katherine. Methods of Mind Training. New York, 1896. BAIL, W. W. R. A Short History of Mathematics. London, 1888.

BASsel.l, C. G. A. Essay on Mathematical Language. London, I787. Bossux, C. Histoire Générale des Mathématiques. (2nd ed.) Paris, I8II.

Bolton, Thaddeus $\mathrm{L}$. Rhythm. Am. Jour. of Psych., Vol. VI, pp. I45-238.

Bolion Thadpeus $L$. The Growth of Memory in School Children. Am. Jour. of Psych., Vol. IV, pp. 362-380. 
Badanes, Saul. The Falsity of the Grube Method. New York, I895, pp. 47 .

BINET, AL,FRED. Psychologie des Grands Calculateurs et Joueurs D'Echecs. Paris, 1894, pp. 364 .

BURKE, F. L. On Committee of Ten. Ed. Review, Vol. X, pp. 282289.

Branson, E. C. Methods of Teaching Arithmetic. Boston, I894, pp. 39.

Badiam, Anna B. Aids to Number. Boston.

Badi,AM, AnNa B. The Child's Number Charts. Boston.

BOHME, A. Anleitung $Z$ un Unterricht in Rechnen. Berlin, 1879 .

Crawleyy, Edwin S. The Origin and Development of Number Systems. Pop. Sci. Monthly, Vol. II, pp. 524-534.

Conant, LeVI L. The Historical Development of Arithmetical Notations. PED. SEM., Vol. II, pp. 149-152.

Conant, Levi L. Text-books in Arithmetic. Ped. Sem., Vol. II, $152-163$.

Conant, Levi $L$. The Number Concept; its Origin and Development. New York, $18 g 6$.

Cal,kin, Mary. A Study of the Mathematical Consciousness. Ed. Review, Vol. VIII, pp. 269-286.

Calikin, Mary. Number Forms. Am. Jour. Psych., Vol. v, pp. 448-453.

CARJORI, Florian. The Teaching and History of Mathematics in the U. S. Washington, I8go.

DELAMBRE, J. B. J. Die Arithmatique der Griechen. Maintz, I8I7. Dhwey and Mclet, ian. Psychology of Number. New York, r895. Dodgrass, Cras. H. Herbart on Mathematics and Natural Science. Ed. Review, Vol. III, pp. 490-494.

DILl,ManN, Von E. Die Mathematik die Fackeltragerin einer neuen Zeit. Stuttgart, 1889 .

Eaton, James S. A Treatise on Arithmetic, Combining Analysis and Synthesis. Boston, $185^{8}$.

EDDy, HeNRy T. College Mathematics. Salem, 1884, pp. 16.

EDGEWORTH, F. Y. Mathematical Psychics. London.

Flourney, Th. Des Phenoménes de Synopsie. Paris, r893.

Gow, J. History of Greek Mathematics. Cambridge, I884.

GiNn, F. B. Addition Manual. Boston, I885, pp. 26.

Galion, Francis. Number-forms. Inquiry into Human Faculty. London, 1883.

GRUBE, A. W. Leitfaden für das Rechnen in der Elementarschule. Berlin, I881.

HAI, AND JASTROW. Studies of Rhythm. Mind, Vol. XI, pp. 55-62.

HoGg, ALEXANDER. More Geometry-Less Arithmetic. Home and School, Vol. II.

HoRnbrook, ADEIIA R. Laboratory Methods of Teaching Mathematics in Secondary Schools. New York, 1895 .

Hornbrook, AdeziA R. Pedagogical Value of Number-forms. Ed. Review, Vol. V, pp. 467-480.

HORNBrook, ADELIA R. Concrete Geometry. New York, i895. 
Hancock, John A. Children's Ability to Reason. Ed. Review, Vol. XII, pp. 26 I-268.

HeRrick, C. L. Notes on Child Experience. Jour. of Comp. Neurology. Vol. V.

Hankel, H. Zur Geschichte der Mathematik. Leipzig, I874.

HoEfer, F. Histoire des Mathematiques. (3rd ed.) Paris, r886.

Holden, Warken. Oneness of Arithmetic. Philadelphia, I893, pp. I6.

IIAS, GRORGF. A Class in Geometry. New York, I894, pp. 46.

Johnson, G. E. Feeble Minded Children. PeD. SEm., Vol. III, pp. 246-3OI.

JACKMAN, WILBUR. Relation of Arithmetic to Elementary Science. Ed. Review, Vol. V, pp. 35-5r.

KaEstner, A. G. Geschichte der Mathematik. Göttingen, 1796.

KEHR, C. Methodik des deutschen Volksschulunterrichts. II \& III. Gothe, 1888 .

KAY, DAvid. Chess-players and Memory of Figures. Memory, What it is and How to Improve it. Paris, I893.

LEFEVRE. Number and its Algebra. Boston, I8g6.

Lindiey and Partridga. Mental Automatisms. Ped. Sem., Vol. V, pp. $4 \mathrm{I}-60$.

Lindlex, ERnest H. A Study of Puzzles. Am. Jour. of Psych., Vol. VIII, pp. 43I-493.

MCLel, AN, J.A. Arithmetic without Quantity. Ed. Review, Vol. $\mathrm{XI}, \mathrm{pp} \cdot 74-80$.

Montucha, J. F. Histoire des Mathematiques. (2nd ed.) Paris, I802.

Macintosh, W. D. Two Paths in Arithmetic. Education, Vol. XVI, pp. $487-489$.

MehNer, Max. Studien, Vol. II, 1884 .

MAURSBargar, C. G. Daserfle Rechnen in Schule and Hous.

Macfarlane, A. Physical Arithmetic Applied Chiefly to Physical Sciences.

Nichols, Herbert. The Psychology of Time. Am. Jour. of Psych., Vol. III, pp. 453-529, and Vol. IV, pp. 60-II2.

Nichor,s, Harbert. Our Notions of Number and Space. Boston, I894, p. 201.

NewToN, H. A. The Metric System. Boston, 1867.

Peterson, El, Is. Arithmetic in Public Schools. Boston, I887, pp. 3 I.

Patrick, G. W. T. Number Forms. Pop. Sci. Monthly, Vol. XIII, pp. 504-5I4.

Pickel, A. Die Geometrie der Dolksschule. Dresden, 1888 .

Prerce, Ella M. Review Number Cards.

PhIllips, D. E. Genesis of Number-forms. Am. Jour. of Psch., Vol. VIII, pp. 506-527.

Quick, R. H. The First Stages in Arithmetic. Iondon, 1888, pp. 15.

RUSSELL, B. On the Relation of Number and Quantity. Mind, Vol. VI, pp. 326-34I.

RUSSE, L, JAMES E. Mathematics in Secondary Schools of Germany. School Review, Vol. II, pp. 479-486 and 549-555.

RIChards, E. L. Old and New Methods in Elementary Geometry. Ed. Review, I892. 
Smith, Margarar K. Review of Jackman's Number Work in Nature Study. School Review, Vo1. II, pp. ro4-106.

Smith, William B. Twel ve versus Ten. Ed. Review, Vol. II, pp. $347-357$.

Smith, Daniel E. Sex in Mathematics. Ed. Review, Vol. X, pp. 84-88.

SERLEY, LEVI. Grube's Method of Teaching Arithmetic. Chicago, 1891 .

Soldan, F. Lours. Grube's Method. Chicago, 1878 .

Sprague, Jesse D. Rapid Addition. Boston, 1892, pp. 39.

SAFFORd, T. H. Modern Teaching in Mathematics. Allantic Monthly, May, I891.

SAFrord, T. H. Mathematical Teaching and its Modern Methods. Boston, 1887, pp. 47 .

SAFford, T. H. The Mathematical Preparation for College. The Academy, 1892 .

SafFord, T. H. Text-books in Arithmetic. PED. StM., Vol. II, pp. $163-168$.

Strivens, Lewis T. On the Time Sense. Mind, Vol. XI, Pp. 393-404.

Scripture, E. W. Arithmetical Prodigies. Am. Jour. of Psych., Vol. IV, pp. 1-59.

Schubert, Harmann. Monism in Arithmetic. The Monist, Vol. IV, pp. 56I-579.

Schuberx, Harmans. Notion and Definition of Number. Monist, Vo1. IV., pp. 396-402.

TUCknR, E. F. Development of the Number Sense. N. Western Jour. of $E d .$, Sept., Dec., Mch., and April, $96-97$.

TUKA, D. H. Insanity of Doubt. Dictionary of Psychological Medicine. London, 1892.

Thin, Ow, JoHn. The Greek Method of Performing Arithmetical Calculations. School and College, 1892.

TyLoR, J. Art of Counting. Primitive Culture, Vol. I, pp. 240-272.

Writing, Margarem C. Individuality of Numerals. PzD. SEM., Vol. II, PP. IO7-IIO.

WALKHR, Francis A. Arithmetic in Boston Schools. Boston, 1887. WUndT. Physiologische Psychologie. Leipzig, I893.

WHITE, E. E. Oral Lessons in Number. New York, $188_{3}$.

Report of the Committee of Fifteen. Boston, 1895.

Report of the Committee of Ten. New York, 1894 .

Review of Cajori's History of Elementary Mathematics. Educational Review, Vol. XIV, pp. I4-I7.

Syllabus for Number Work, Indian Schools. Washington, 1894.

Hindoo Arithmetic. Science, Vol. XXV, p. 234. 